NBER WORKING PAPER SERIES

\title{
DESIGNING BENEFITS FOR PLATFORM WORKERS
}

\author{
Jonathan Gruber \\ Working Paper 29736 \\ http://www.nber.org/papers/w29736 \\ NATIONAL BUREAU OF ECONOMIC RESEARCH \\ 1050 Massachusetts Avenue \\ Cambridge, MA 02138 \\ February 2022
}

I am extremely grateful to Miriam Chaum and Libby Mishkin for their guidance and suggestions, and to Mariya Shappo and Sanat Kapur for data analysis and Julie Dorshkind for survey research support. This research was funded by, and the author was compensated by, Uber Technologies. Employees of Uber provided feedback and comments on the paper and had the right to review the paper for factual accuracy, but did not have editorial control over the content. The views expressed herein are those of the author and do not necessarily reflect the views of the National Bureau of Economic Research.

NBER working papers are circulated for discussion and comment purposes. They have not been peer-reviewed or been subject to the review by the NBER Board of Directors that accompanies official NBER publications.

(C) 2022 by Jonathan Gruber. All rights reserved. Short sections of text, not to exceed two paragraphs, may be quoted without explicit permission provided that full credit, including (C) notice, is given to the source. 
Designing Benefits for Platform Workers

Jonathan Gruber

NBER Working Paper No. 29736

February 2022

JEL No. I13,J32,J41

\begin{abstract}
Designing benefits for the growing platform workforce in the U.S. poses significant challenges. While platform workers need protection against unforeseen shocks, work that is often part time and spread across multiple platforms makes the traditional benefits model untenable. This paper reports the results from a survey of drivers and couriers working with Uber to help understand their benefits preferences. We find that there is a wide diversity across these workers in platform earnings, the share of platform earnings from Uber, the share of family earnings from platform work and the availability of benefits from other jobs. We use willingness-to-pay questions to show that workers are willing to trade off additional income for benefits; after accounting for the tax advantage of benefits, workers are roughly indifferent on average between the two. While there are some trends in valuation, such as higher valuation for pension than for health contributions, the most notable feature of the data is the wide variation across workers in their preferences across benefits types and relative to income. Workers also show a preference for benefits that can help them commit to increase savings in the future.
\end{abstract}

\author{
Jonathan Gruber \\ Department of Economics, E52-434 \\ MIT \\ 77 Massachusetts Avenue \\ Cambridge, MA 02139 \\ and NBER \\ gruberj@mit.edu
}


The twenty-first century has seen significant growth in the "platform workforce": workers who complete tasks via apps or platforms that allow the worker to control their own schedule. As of August, 2021, 16 percent of Americans had ever earned money from platform work. ${ }^{1}$

This new form of work raises a number of challenging issues for labor market policy. Among them are how to ensure that platform workers have access to what have typically been employee benefits such as health insurance, pensions, vacation time and sick and family leave. These benefits serve an important function: many workers have very low savings and can find themselves unprepared for a drop in their earnings, family illness or retirement. There are a variety of reasons, ranging from behavioral economics to incomplete markets, why workers will not save optimally on their own for these conditions. And past research shows that assistance from employers can help - particularly if employees are defaulted into plans such as employer pensions. However, empirical evidence suggests that the cost of these benefits are largely passed on to workers in the form of lower wages. ${ }^{2}$ While benefits offered by employers have become less generous over time, they still remain the dominant source of protection against health and many other risks.

Creating a parallel model for benefits in the platform economy is complicated. In the traditional labor market, employers provide these benefits to their full-time workers after some period of attachment to the firm. Workers in the platform economy value the flexibility of being able to vary their hours across platforms and over time. ${ }^{3}$ This raises a host of difficulties around applying the traditional benefits model, such as defining who has enough attachment to a firm to merit benefits, and providing benefits when work is spread across multiple employers or platforms.

\footnotetext{
${ }^{1}$ Data from Pew Research's "State of Gig Work in 2021." Available at: https://www.pewresearch.org/internet/2021/12/08/the-state-of-gig-work-in-2021/.

${ }^{2}$ Gruber (2001).

${ }^{3}$ See, for example, Chen et al. (2019).
} 
One alternative to the traditional benefits model is to move to a more flexible approach that allows multiple work platforms to contribute to a benefits fund for workers. This benefits fund can then in turn be either fully flexible or restricted in various ways. Gruber (2016) suggests such a model for the specific case of short-term financial security. But designing such a fund is difficult and raises a number of challenging issues.

The goal of this paper is to provide some background and new evidence to help inform policy debates over the proper benefits model for platform workers. I begin by reviewing in more detail the challenge of providing benefits to platform workers. I discuss the economic case for ensuring provision of benefits by firms. But I also raise a number of natural challenges that arise in providing benefits to workers with flexible multi-firm work arrangements.

Since benefits do not come for "free", but rather result in lower compensation in other areas, understanding the value of these benefits to platform workers is critical. So I next turn to a new survey of drivers on Uber's rideshare and delivery platforms which gathers data on their work arrangements, income (from Uber and elsewhere) and existing benefits coverage. I include a variety of questions designed to solicit these drivers' valuation of benefits relative to additional cash compensation, which allows us to understand both overall benefits valuation and the relative value across benefits categories.

Our findings are quite interesting. First, there is a fairly bimodal distribution of earnings from platform work, with most workers making relatively little but a sizable share making more than $\$ 30,000$ per year; more than a quarter of the sample earns less than 5 percent of their income from platform work, while about one-fifth of the sample earns more than 50 percent of their income from platform work. Most drivers are insured, but the rate of uninsurance is higher than the 
national average for workers; about half have retirement savings, which is more comparable to national averages.

Most workers value benefits at a lower level than the equivalent cash payment. But after considering the tax advantage of benefits, the valuation is roughly equal - with a sizable share preferring benefits even to an equivalent raise. There is a clear preference for retirement savings over other forms of benefits, while contributions towards health care or health insurance are valued least highly. But perhaps the most important conclusion is that there is an incredible diversity of views of both the absolute and relative value of benefits among this population. Workers also show a preference for benefits that can help them commit to increase savings in the future.

\section{The Challenge of Benefits for Platform Workers}

The U.S. has traditionally relied on employers to provide employee benefits. The origin of this system lies in both the enormous political challenges faced by efforts to provide universal government-provided benefits, such as single payer health insurance, and the use of employer benefits as a means of compensating employees that could evade wage and price controls in World War II. ${ }^{4}$

The traditional U.S. benefits model is that most employees have one primary employer from which they get their benefits. Fifty years ago, a typical benefits package at a large firm would include a defined benefits pension plan (e.g., where benefits are tied to the worker's earnings and tenure with the firm, not their contributions), very generous health insurance coverage for the family (with small or no deductibles, largely free for the worker's own coverage but with the worker paying as much as 25 percent of family costs), paid vacation and sick leave.

${ }^{4}$ Gruber (2008). 
Over time, benefits have evolved in traditional firms to become more flexible but less generous. Pensions are now defined contribution, whereby the benefits depend on contributions by employers or on employee self-determined withdrawals from pay through a $401(\mathrm{k})$ account. Pensions of either type are offered to 72 percent of employees and 56 percent participate. ${ }^{5}$

Employer-sponsored health insurance (ESI) coverage has eroded significantly as well. The share of private-sector workers enrolled in ESI has fallen from 65 percent in 2001 to 57 percent in 2020. Worker contributions to ESI plans have risen from an average of $\$ 355$ to $\$ 1,243$ over this period, while the share of plans with no deductible has fallen from 45 percent in 2006 to 17 percent in 2020 , and the average size of the deductible rose from $\$ 584$ to $\$ 1,644$ over that time. ${ }^{6}$

Vacation and sick time benefits have remained roughly constant over the past decade, with the mean paid vacation days after one year's service steady at 11 days and the mean paid sick days after one year's service steady at 8 days. ${ }^{7}$

To date, in the U.S., workers in the platform economy are not categorized as employees but rather as independent contractors - and as such they have not been provided benefits. Workers without adequate benefits - whether employees or independent contractors - face several key challenges.

The first is retirement preparation. Retirement is often unplanned; health problems, caring for family and forced retirement contributes to the timing of retirement for nearly half of retirees. And one-fourth of non-retirees indicated that they have no retirement savings, and fewer than 4 in 10 non-retirees felt that their retirement savings are on track. Moreover, nearly 6 in 10 non-retirees

\footnotetext{
${ }^{5}$ Data from the 2021 BLS National Compensation Survey. Available at: https://www.bls.gov/news.release/pdf/ebs2.pdf.

${ }^{6}$ Data from the 2020 KFF Employee Benefits Survey. Available at: https://www.kff.org/healthcosts/report/employer-health-benefits-annual-survey-archives/.

${ }^{7}$ Data from the 2020 BLS National Compensation Survey. Available at: https://www.bls.gov/news.release/archives/ebs2 09242020.pdf.
} 
with self-directed retirement savings expressed low levels of comfort about making retirement decisions. ${ }^{8}$ Among nontraditional workers in particular, 30 percent had saved for retirement in only some months, rarely or never in the past 12 months. ${ }^{9}$

The second is health spending risk. Uninsured workers face significant spending risk given the high cost of health care in the U.S. For those not offered health insurance by their employers, subsidized insurance is available on the Affordable Care Act (ACA) exchanges. The cost of that insurance is capped as a share of income for workers below 400 percent of the Federal Poverty Line, or roughly $\$ 50,000$ for an individual and $\$ 100,000$ for a family of four; under the recently passed American Rescue Plan, those subsidies have been increased and extended to all incomes. But most who are uninsured choose to remain so rather than sign up for the exchanges. The result can be medical debt or reductions in needed medical care. Twenty-five percent of adults skipped medical care, such as a visit to a doctor or dentist, in 2019 because they were unable to afford the cost, and 22 percent incurred a major unexpected medical expense during the year. Meanwhile, eighteen percent of adults had unpaid debt from their own medical care or from medical care for a family member. ${ }^{10}$

The third is the risk of short-term income fluctuations arising from factors outside the worker's control, in particular own or family illness. The Federal government mandates shortterm unpaid family and medical leave, while a large share of employers offer paid leave for family and medical leave. This short-term protection is important because most families in the U.S. do

\footnotetext{
${ }^{8}$ Data from the Federal Reserve. Available at: https://www.federalreserve.gov/publications/files/2019-reporteconomic-well-being-us-households-202005.pdf.

${ }^{9}$ Data from the 2020 Pew Survey of Nontraditional Workers and Retirement Savings. Available at: https://www.pewtrusts.org/-/media/assets/2021/04/pew-survey-of-nontraditional-workers-and-retirement-savingstopline-results.pdf.

${ }^{10}$ Data from the Federal Reserve. Available at: https://www.federalreserve.gov/publications/files/2019-reporteconomic-well-being-us-households-202005.pdf.
} 
not have the financial assets available to weather such short-term fluctuations. Sixteen percent of adults are not able to pay all of their current month's bills in full, and more than one-third of adults say that they could not cover an unexpected expense of $\$ 400$ completely using cash or a credit card that they could pay off. ${ }^{11}$

Strengthening benefits for platform workers would help to close some of the gaps identified above. However, addressing these concerns for platform workers through the traditional route of employer financing is challenging for a number of reasons.

First, benefits are traditionally tied to specific firms - this is true of "lumpy" benefits like health insurance, but it can also be hard to combine even "proportional" benefits like retirement savings contributions that are directed into different accounts. These structures are incompatible with platform work given that many platform workers spread their work effort over multiple firms, both within and outside the platform economy. As we show below, the typical driver on Uber also works on other platforms; 60 percent make at least some of their platform earnings from non-Uber platforms, and 35 percent make a large amount from those other platforms. And nearly half of drivers work either part or full time at a traditional job.

Furthermore, many platform workers voluntarily come in and out of work rather than steadily working for a firm. Consider the sample of drivers who were active on Uber at the start of a quarter, and who work during that quarter. Of that group, only 22 percent work $20+$ hours for four consecutive weeks; only 13 percent work 30+ hours for four consecutive weeks. Moreover, less than 5 percent of such workers work $20+$ hours every week in a quarter, and only 2 percent work $30+$ hours every week in a quarter. ${ }^{12}$

\footnotetext{
${ }^{11}$ Data from the Federal Reserve. Available at: https://www.federalreserve.gov/consumerscommunities/sheddataviz/unexpectedexpenses.html.

12 Uber internal data for Q2 2021.
} 
Even if platform workers were reclassified as employees, most employers only provide benefits to full-time employees who have been steadily employed there for some period of time. For instance, among private-sector employees eligible to be covered by an employer-sponsored health plan, 68 percent faced a waiting period, with the average waiting period lasting 1.9 months. ${ }^{13}$ Similarly, even in those jurisdictions where employers are required to offer paid sick leave, employees often need to wait 90 days before beginning to use their accrued leave. ${ }^{14}$ Meanwhile, 81 percent of full-time employees have access to retirement benefits as compared to 42 percent of part-time employees. ${ }^{15}$ Only 11 percent of firms offering health insurance benefits extend those offerings to their part-time employees. ${ }^{16}$

To summarize, traditional employee benefits remediate some key risks faced by workers. But standard models run into some challenges when applied to the platform economy. This suggests potential tradeoffs in assessing the role of benefits in this sector.

\section{The Uber Survey of Benefits Preferences}

To better understand these questions, I worked with Uber to design a survey of rideshare and delivery drivers on its platform. We worked with the survey firm Dynata to implement a survey of drivers between July 1 and 15, 2021. In order to ensure candid responses, drivers were assured confidentiality and were not told who was sponsoring the research. We targeted active

\footnotetext{
${ }^{13}$ Data from the 2020 KFF Employer Health Benefits Survey. Available at: https://files.kff.org/attachment/ReportEmployer-Health-Benefits-2020-Annual-Survey.pdf.

${ }^{14}$ Based on a review by A Better Balance. Available at: https://www.abetterbalance.org/paid-sick-timelaws/?export.

${ }^{15}$ Data from the BLS National Compensation Survey. Available at: https://www.bls.gov/ncs/.

${ }^{16}$ Data from the 2020 KFF Employer Health Benefits Survey. Available at: https://files.kff.org/attachment/ReportEmployer-Health-Benefits-2020-Annual-Survey.pdf.
} 
drivers in the U.S. outside of California ${ }^{17}$, which we define as those who completed at least four rideshare or delivery trips on the Uber platform in June 2021. Drivers were offered a \$10 Amazon e-gift card as an incentive, and we obtained 1,063 responses - a response rate of $0.34 \%$ - which were weighted to match the relevant population.

Our survey consisted of two parts. The first provided background on the drivers, including data on:

- Demographics: age, gender, race, ethnicity, marital status, household size

- Platform jobs: type of jobs, companies worked with, when worked, plans to continue, earnings, distribution of earnings across apps

- Other income: other jobs/work status, other earnings, family income

- Benefits: health insurance (coverage, source, costs, reasons why no coverage), retirement savings accounts, availability to finance $\$ 400$ or $\$ 1,000$ emergency expense

Recognizing the potential sensitivity of income questions, when asking about total earnings from app-based work, we asked first for the absolute amount, and if individuals were unwilling to provide that, we asked about earnings in ranges. In fact, however, 89 percent of individuals answered the direct earnings question; for the remainder, we imputed the middle of the reported range.

The second part of the survey collected data on their preferences on contributions to a benefits fund. Our goal in this part of the survey was to understand how workers valued contributions to a benefits fund relative to receiving cash - as well as to understand how they valued benefits relative to each other.

${ }^{17}$ California was excluded in order to avoid conflating the hypothetical benefits being asked about with the benefits drivers currently receive under Proposition 22. 
To do so, we structured a series of questions that asked workers explicitly about their valuation of various benefits relative to cash. In order to make this manageable and avoid respondent confusion, we randomly divided the sample into three groups and asked each third of the sample separate questions about their valuation of retirement benefits, health benefits and sick or family leave benefits, respectively.

To begin, for each worker, we computed an amount that might be contributed to such an account. We computed this "potential contribution" as 5 percent of their reported earnings across all of their app-based jobs. Suppose for example for a given worker that was $\$ 1,000$. We then asked questions of the following form:

Now imagine that you are offered a choice. Each year, in addition to your typical rideshare/delivery earnings, you could get $\$ 670$ in cash or get $\$ 1,000$ in a retirement savings account. Your investment returns in the retirement savings account would be tax-free, but you could face a penalty if you withdraw funds before you reach retirement age. Which would you prefer?

Individuals were first offered a choice of receiving either this potential contribution in the form of the benefit (in this case retirement contributions) or two-thirds of that amount in cash. If they stated that they preferred cash, then we lowered the cash offer. If they said that they preferred benefits, we raised the cash offer. In this way we created bounds of the valuation of the specific benefit (e.g., retirement contributions) relative to cash.

Another one third of the sample was asked a similar question regarding health benefits: Now imagine that you are offered a choice. Each year, in addition to your typical rideshare/delivery earnings, you could get $\$ 670$ in cash or get $\$ 1,000$ in a special account that can only be used for health spending: for example, on health insurance 
premiums, doctor's visits, or prescriptions. If you didn't have any health expenses that year, the money would roll over to the next year. Which would you prefer?

Finally, the last third of the sample was asked a similar question relative to sick and family leave:

Now imagine that you are offered a choice. Each year, in addition to your typical rideshare/delivery earnings, you could get $\$ 670$ in cash, or $\$ 1,000$ that you can access if you need to take time off due to illness or injury, or to care for a family member. If you didn't take time off that year, the money would roll over to the next year. Which would you prefer?

We then asked all individuals a question which allows us to compare their preferences for the specific offered benefits versus a generally flexible account. We asked all respondents:

Now imagine you are given a different choice. Each year, in addition to your typical rideshare/delivery earnings, you could get $\$ 670$ in cash, or $\$ 1,000$ in a flexible benefits account that you can access for sick or family leave, for any health expenses, or to direct into a retirement savings account (or for any combination of these things). If you didn't claim it, the money would roll over into the next year. Which would you prefer?

We concluded by exploring two additional questions which are relevant to the design of a potential benefits fund. First, we explored how drivers felt about the potential use of funds remaining in their benefit accounts if they were not used up by the end of the year. We allowed respondents to rank their preferences over using the remaining funds across several options:

1. Roll the remaining money over to the next year for the same purpose

2. Roll the remaining money into a retirement savings account 
3. Roll the remaining money over to the next year for the same purpose, until you accumulate a large amount at which point additional funds are directed to a retirement savings account

4. Automatically deposit any remaining money into your bank account at the end of the year

Finally, we explored the potential interest of drivers in an approach pioneered by economists Richard Thaler and Shlomo Bernartzi (2004): the "save more tomorrow" plan. The motivation behind this approach is the recognition that many workers would prefer not to reduce their incomes today in order to save, but would like to have more savings in the future. So the plan asks workers to commit to saving future raises, allowing them to not trade off current incomes but to create a savings balance. This plan was very popular among workers to whom it was offered and it significantly increased worker savings rates.

To evaluate the interest in a comparable option among respondents, we asked them about a program which would help them save amounts above a weekly earnings target. In particular, we asked half of respondents about saving into a flexible benefits account:

For the final scenario, imagine you have the chance to participate in a program that helps you save more. You would choose a weekly earnings target for your earnings from all ridesharing/food-delivery apps, and if you exceeded that target, any additional earnings would be automatically transferred into a flexible benefits account.

For example, if you set your target at $\$ 500$ for the week, and you made $\$ 500$ or less, nothing would happen. But if you made $\$ 600$, the extra $\$ 100$ would be put into this new account. The money in this account could be used for paid time off, health 
expenses, or retirement. If you didn't use it by the end of the year, the fund would roll over to the next year. Would you choose to participate in this program?

The other half of respondents were asked a similar question, but the extra earnings would be transferred to a retirement account:

For the final scenario, imagine you have the chance to participate in a program that helps you save more for retirement. You would choose a weekly earnings target for your earnings from all ridesharing/food-delivery apps, and if you exceeded that target, any additional earnings would be automatically transferred into a retirement account. For example, if you set your target at $\$ 500$ for the week, and you made $\$ 500$ or less, nothing would happen. But if you made $\$ 600$, the extra $\$ 100$ would be put into this new account. Your investment returns in the retirement savings account would be taxfree, but you could face a penalty if you withdraw funds before you reach retirement age. Would you choose to participate in this program?

We then followed up by asking whether the interest in participating would rise if contributions were matched, and we asked where the target was set.

\section{Results: The Characteristics of Drivers on the Uber Platform}

In this section, I review the results from the first part of our survey, measuring the demographic, income and benefits coverage of active drivers. Where possible, I compare this population to the characteristics of all U.S. workers. All survey responses were weighted to match the demographic and driving behavioral characteristics of the active driver population on Uber in the United States outside California as of June 24, 2021. 
Table 1 presents the demographics for the sample and the full sample of U.S workers. ${ }^{18}$ More than three-quarters of drivers are between 25 and 54, which is higher than for all workers. The sample is 70 percent male, which is dramatically different from the 53 percent of all U.S. workers who are male. 51 percent of the sample is white, with large representation from Black and Hispanic drivers; this is a much higher level of diversity than the U.S. workforce as a whole, where 61 percent of workers are white. Almost half of the sample are caregivers, which is very close to the national total. And the education distribution of the sample is quite different than the workforce as a whole, with a much smaller share of the sample being high school dropouts, a much higher share having technical degrees or some college, and a much smaller share having graduate degrees. Finally, 42 percent are married, which is slightly lower than the average of 50 percent for the workforce as a whole.

Table 2 shows the geographic distribution of respondents. Relative to the overall distribution of U.S. workers, the sample is much more likely to live in the South Atlantic, somewhat more likely to live in the Middle Atlantic and less likely to live in the West North Central (e.g., Iowa, Kansas, Minnesota, Missouri, Nebraska and North/South Dakota).

Our sample consists of those who have driven with Uber, but this includes both Uber and Uber Eats, and many do platform work in other contexts as well. Figure 1 and Table 3 explore this distribution in two ways. Table 3 shows the share of the sample that does each kind of platform work, even if they do multiple types. Three-quarters of the sample provides food delivery, 57 percent provide rideshare services, and 38 percent deliver groceries; there is a small share who undertake platform work in other areas. Figure 1 shows the joint distribution across the three main categories. Less than one-half of the sample provides only one service. Forty percent provide two

\footnotetext{
${ }^{18}$ Demographic data for U.S. workforce from www.bls.gov.
} 
services, with large overlaps between rideshare and food delivery and between food and grocery delivery. Finally, 16 percent of the sample participates in all three types of platform work.

And while our sample is based on those who worked with Uber, many individuals in our sample work with other platforms as well. The distribution of the companies is shown in Table 4. We see that more than 25 percent of the sample works with Lyft, Postmates or DoorDash, while more than 10 percent work with GrubHub, Instacart and Amazon Flex. So there is a wide distribution across platforms. Figure 2 shows a histogram for working with $0,1,2$ or more than 2 companies beyond Uber. There is a wide distribution, with the most working with 1 other platform, but large shares in each category.

Figure 3 shows the distribution of annual earnings from all rideshare and food delivery work, including all tips and promotions but before subtracting expenses. About 46 percent of drivers make less than $\$ 5,000$ per year from platform work. Another 16 percent make $\$ 5-10,000$ per year. The next largest group are those who make more than $\$ 30,000$ per year (13 percent). Only about 25 percent of drivers make between $\$ 10,000$ and $\$ 30,000$. Interestingly, the smallest group is those making $\$ 15-\$ 20,000$ per year.

Figure 4 shows the distribution of those earnings across apps. Forty-one percent of the sample earns their entire amount using only Uber. ${ }^{19}$ Another 25 percent earn a small amount (less than 20 percent) from other apps. The remaining 34 percent of the sample either earns a large amount on other apps or uses multiple apps sufficiently that there is no clear primary app.

Table 5 accounts for the other activities undertaken by drivers besides ridesharing and food delivery; individuals may be in more than one category. Only 18 percent of the sample works only on ridesharing/food delivery platforms. On the other hand, 40 percent of the sample provides

\footnotetext{
${ }^{19}$ Note that Figure 2 refers to the entire work history, while Figure 4 refers to the last year, which is why the share with Uber earnings only is higher in Figure 4.
} 
platform services on top of full-time employment in a "traditional" job; another 9 percent provide these services on top of part-time employment. Thirteen percent of the sample are also students, while 9 percent own their own business. Eleven percent of the sample are unemployed, while 5 percent are retired and 7 percent record themselves as primarily caregivers.

Figure 5 shows the distribution of other earnings for drivers. This question is only asked of those who report that they are working full or part time, doing other platform/freelance work or are running their own business. As a result, a very small share of individuals report zero earnings, indicating that they either answered the question about work status or earnings incorrectly, or that they run their own business and have no income. Twenty-six percent of the sample earns less than $\$ 10,000 /$ year from other jobs. On the other hand, almost one-third of the sample earns more than $\$ 50,000 /$ year, with 7 percent earning more than $\$ 100,000 /$ year.

Figure 6(a) shows the distribution of family income for the sample, which is quite wide: 12 percent of the sample live in families with income below $\$ 10,000 /$ year, while more than 18 percent live in families with income above $\$ 100,000$. The distribution is fairly flat across categories, although the category ranges are wider at the top.

For a different perspective, Figure 6(b) rescales the distribution as a share of the poverty line ${ }^{20}$; this allows us to account for family size as larger families have higher poverty lines. Almost 25 percent of the sample lives below poverty, but almost another 25 percent live above 4 times the poverty line.

Figure 6(c) shows the distribution of the share of family income that comes from rideshare or food delivery. More than a quarter of the sample earns less than 5 percent of their household's

\footnotetext{
${ }^{20}$ Poverty threshold data is from the Census Bureau, available at https://www.census.gov/data/tables/timeseries/demo/income-poverty/historical-poverty-thresholds.html.
} 
income from platform work, and only about one-fifth of the sample earns more than 50 percent of their income from platform work.

Since our report is focused on the design of benefits for platform workers, we next turn to analyzing the existing coverage of benefits for the workers in our sample, in Tables 6 and 7 . Seventy-seven percent of our sample is insured, which is well below the national rate for workers of 89 percent. ${ }^{21}$ Among those who receive insurance, 37 percent receive it through their employer and 15 percent through a family member's employer, while 31 percent have public insurance. Interestingly, the monthly reported costs of insurance for those with employer insurance are about the same as those who buy it on their own, despite the fact that employers pay some of the costs of insurance, highlighting the fact that those with employer insurance typically have much more generous insurance than do those who buy it on their own.

Among those who are uninsured, the primary reason offered is cost, with 80 percent of the sample saying that costs are too high (although individuals can provide more than one answer so that the total is more than 100 percent). Interestingly, Table 7 shows that the lower rate of insurance coverage among drivers is not due to the age, marital status, race or education of the sample - in each cell, the insurance coverage rate is lower for drivers.

We also consider the retirement savings and liquid savings available to those in our sample. As Table 8 shows, about half of our sample has some kind of retirement savings account, with most having a 401(k) account. The table also shows comparable figures for all U.S. workers, which are considerably higher.

In addition, as Figure 7 and Table 9 show, there is a very low level of liquid savings in our sample, comparable to the U.S. population. The first bar shows that more than one-third of drivers

${ }^{21}$ Data from www.bls.gov, which reports health insurance coverage separately for professional and other workers and the shares of workers in each group. 
(compared to 36 percent in the general population ${ }^{22}$ ) cannot cover $\$ 400$ of emergency expenses using cash, savings or a credit card. Another 17 percent can cover $\$ 400$ in expenses, but not $\$ 1,000$. As a result, less than one-half the sample can cover $\$ 1,000$ in unexpected expenses.

\section{Results: Benefits Preferences}

A major goal of our survey was to assess the value that platform workers place on benefits. To do so, we asked a set of questions, described above, to assess reported valuation of benefits relative to an equivalent amount of cash earnings. Figure 8 shows the results of those assessments for the range of benefits that we consider.

The figure has six groups of vertical bars. Within each group, there are bars representing results for health care benefits, retirement benefits, sick leave and flexible accounts. The groups are, from left to right:

- the share of the sample that values that benefit at less than 25 percent of its cash equivalent;

- the share of the sample that values that benefit at between 25 and 50 percent of its cash equivalent;

- the share that values that benefit at 50-67 percent of its cash equivalent;

- the share that values that benefit at 67-85 percent of its cash equivalent;

- the share that values that benefit at $85-100$ percent of its cash benefit;

- the share that values the benefit above its cash equivalent.

For example, consider health care benefits (the red bars). Almost 30 percent of respondents report that they value health care benefits so little that they would rather have less than 25 percent

\footnotetext{
${ }^{22}$ Data from the Federal Reserve. Available at: https://www.federalreserve.gov/consumerscommunities/sheddataviz/unexpectedexpenses.html.
} 
of the equivalent in cash; that is, 30 percent of respondents would rather have $\$ 250$ in cash than $\$ 1,000$ in health care benefits. Fourteen percent value health insurance benefits at between 25 and 50 cents on the dollar; 18 percent at between 50 and 67 cents; 10 percent at between 67 and 85 cents; and 9 percent at 85 cents to one dollar. There are one-fifth of workers who would prefer a dollar of health care benefits to a dollar of cash. Overall, however, workers appear to not place much value on health care benefits.

On the other hand, there is a somewhat higher valuation on retirement benefits. Fewer than 20 percent have essentially no value on retirement benefits, and more than 30 percent value them at more than dollar for dollar. Sick and family leave benefits are valued more than health care benefits as well, but less than retirement benefits.

What is quite surprising is that workers do not value flexible benefits much more highly than retirement benefits. The purple and green bars are very similar in each case; a few more workers value retirement at close to zero, but a few more also value retirement at more than a dollar. This suggests relatively high demand for retirement benefits.

The next two panels of the figure compare those who work full time for another employer versus those who do not; the former group is more likely to have benefits already provided. Indeed, those with other full-time work are more likely to say that they have little value for health benefits, although the differences are not particularly noticeable.

The next two panels do the same for those without other health insurance and those without retirement savings. Among respondents without health insurance, the valuation of health benefits shifts to the right. For example, across all workers, significantly more value health insurance at less than $0.25 \mathrm{x}$ in cash than always prefer it; but among those without health insurance, this reverses. Interestingly, the differences are much weaker for those with and without retirement 
accounts. This suggests that having health insurance from another job greatly mutes the value of additional health protection, but having retirement insurance from another job does not greatly mute the value of additional retirement savings.

This figure is hard to summarize, so we turn to a different approach next. Here, we account for the tax favoritism shown to many employee benefits. To do so, we use the NBER Taxsim tax calculator to assign a marginal tax rate to each individual in our sample. ${ }^{23}$ We then compare the pre-tax value of benefits to the after-tax value of cash equivalent. Of course, this is imperfect, since some benefits are fully tax preferred (e.g., health insurance), others are simply tax deferred (retirement benefits), and others are taxed as income (e.g., sick pay). But to the extent that workers think of benefits generally as pre-tax, this may be a better approximation of their valuation.

The nature of the survey questions does not allow us to calculate the exact valuation of benefits - e.g., a respondent may state that they prefer $\$ 85$ in cash to $\$ 100$ in benefits, but we do not know their exact indifference point. However, we are able to calculate the lower and upper bound of the valuation. For example, suppose a respondent says that they prefer $\$ 100$ in benefits to $\$ 67$ in cash, but that they prefer $\$ 85$ in cash to $\$ 100$ in benefits. Then an "upper bound" valuation on benefits would use the $\$ 85$ figure - i.e., we assume that this example respondent is indifferent between $\$ 85$ in cash and $\$ 100$ in benefits. This allows us to compare the pre-tax cash amount ( $\$ 85 /(1$-marginal tax rate)) to $\$ 100$ in benefits; if the pre-tax cash amount is greater than $\$ 100$, we conclude that the respondent prefers $\$ 1$ of benefits to $\$ 1$ of cash. A "lower bound" calculation would instead use $\$ 68$ - i.e., assuming that the respondent was almost at their point of indifference at $\$ 67$. A “middle ground" calculation uses the midpoint of the range - so in this case it would be $\$ 76$.

\footnotetext{
${ }^{23}$ See www.nber.org/taxsim. Our tax imputations are by definition imperfect since we do not know many of the elements of taxable income.
} 
The results of these calculations are shown in Panel A of Figure 9, with three figures for upper, middle and lower bounds. For the upper bound, we find that a majority of workers prefer most forms of benefits to cash - but not health insurance, which is, even after the tax benefit, still worth less than a cash equivalent for most respondents. At the lower bound, cash is always preferred. In the middle ground case, retirement and flexible benefits are preferred to cash, but health insurance and sick leave are not.

We then show the results restricted to those without health insurance and those without retirement coverage, in Figure 9 Panel B; we just show the upper bound here, although the trends across the bounds from previous graphs hold here as well. The results echo the conclusions above. With respect to health insurance, the figures line up as expected. Workers without health insurance do value health insurance more highly: whereas for all workers, even after accounting for taxes, cash is preferred to insurance, for those without health insurance the insurance is preferred. But workers without retirement coverage seem to value retirement coverage less highly than all workers; retirement coverage is still preferred, but only marginally. Once again, this suggests that health insurance is a much more highly valued add-on for those without insurance, but that additional retirement savings is valued more equally by all.

While we emphasize the aggregate valuation of benefits from these questions, what stands out the most is the diversity of preferences across benefits types. To illustrate this more directly, we asked all participants for their rankings across benefits options. Figure 10 shows all possible configurations:

- Health first, retirement third, sick third

- Health first, sick second, retirement third

- Retirement first, health second, sick third 
- Retirement first, sick second, health third

- Sick first, health second, retirement third

- Sick first, retirement second, health third

The resulting dispersion shows that at least one-tenth of the sample prefers each of these options. The most preferred option (retirement, then sick leave, then health) is only preferred by one-quarter of the sample, or less than three times the least preferred option.

We next move on to assess how much workers value flexibility. Figure 11 shows the result of asking workers if they prefer to have flexible allocation of benefits dollars versus allocation exclusively into benefits, first for health, then for retirement, then for sick leave. What is quite striking is the large share of workers that are indifferent. For retirement benefits, more than onesixth of workers would prefer an inflexible arrangement, perhaps reflecting their assessment of self-control problems with savings; for health benefits and sick and family leave, a much smaller share would like to be committed to having money devoted to that category.

Another key issue with benefits funds is that with flexible funds, workers may not use up all their money in a given year. This raises the question of worker preferences over what happens to those unused funds. Figure 12 explores this, using a 1-4 ranking where lower is better. The most popular option is to have excess funds deposited in a bank, but there are a large number of individuals who would want the funds rolled over, in particular if they are rolled over for the same purpose before eventually becoming retirement savings. This once again suggests the value that workers appear to place on the commitment device provided by putting money into a separate retirement account rather than translating to cash.

Finally, we assess worker demand for a "save more tomorrow" type option in Table 10. As discussed above, we first ask workers if they would like to participate in an account where 
earnings above a target amount are deposited into either a flexible or retirement amount. Fiftyeight percent say that they would value this arrangement into a flexible account, and 54 percent into a retirement account, suggesting worker demand for this type of savings commitment. On the other hand, the volunteered cutoff amounts are very high, at \$601-\$774/week, or 213 to 264 percent of average weekly earnings ${ }^{24}$. So workers would like commitment, but only for very extreme positive earnings shocks.

As the last row shows, among those who show no interest in the account, 44 percent would agree to participate if matched one for one, but once again with a fairly high cutoff of 180 percent of average weekly earnings. So a matched commitment program would attract a total of roughly 80 percent of workers and raise savings in periods of very high earnings.

\section{Implications}

Benefits such as health insurance and retirement plans are a central feature of the modern employer-employee relationship, particularly for large firms. Yet translating this model over to platform workers, while maintaining their flexibility across work options, presents a number of challenges. In this paper, I provide some background which can help address those challenges.

This novel set of results has interesting implications for the design of benefits for platform workers. First, worker preferences across benefits are very diverse, both in absolute and relative valuation. For example, about one-fifth of workers would rather have 25 cents in cash than a dollar of benefits - but at the same time, about 25 percent would rather have a dollar in benefits than a dollar in cash. Moreover, there is a wide ranking of preferred benefits. Overall, workers

\footnotetext{
${ }^{24}$ The average target dollar amount includes all responses except 1 percent of extreme values. For the purposes of expressing this as a percent of average weekly earnings, only those respondents who earned all of their rideshare/delivery income on Uber are included. Weekly earnings are from Uber administrative data and are calculated as the average weekly earnings over the last 12 months among weeks with nonzero earnings.
} 
consistently value retirement savings more highly than other benefits, particularly health insurance coverage - partly because 80 percent of workers have health insurance from another source, but partly since workers appear to value the ability of retirement accounts to help "commit" them to savings. But when asked to rank benefits, there is no clear consensus, with the most common combination getting support from only about 25 percent of workers.

Second, platform workers spread their time widely across platforms. Seventy-five percent of drivers sampled from Uber have worked with at least one other platform company, and more than 40 percent have worked with 2 or more. This suggests that benefits provision in the platform economy is best shared as a burden across multiple firms, rather than being provided on a platformby-platform basis. Contributions from platform companies in proportion to worker earnings could equitably fund this burden.

Finally, platform workers value the commitment provided by retirement savings that is withheld from earnings. There is even substantial enthusiasm for an option that allows workers to devote a share of earnings from high earning weeks towards a retirement savings account; if such contributions were matched, 80 percent of workers would like to use such a mechanism. Such default mechanisms could lead to higher savings among platform workers.

These findings have important implications for policy makers considering how to design benefits for this sector. Workers are definitely interested in having benefits and appear, on average, willing to sacrifice the equivalent amount of income to get them - and these benefits create advantages for society above and beyond the value to the worker, for example through reducing the cost of caring for the uninsured or indigent retirees. As a result, there may be a role for the government in ensuring that workers have access to benefits through platform work, either through 
mandating benefits, ensuring tax subsidization or helping offset setup and coordination costs across companies.

At the same time, the enormous diversity of preferences of workers reported in these data suggest that the government may not have a compelling case for mandating particular benefits, as opposed to a flexible fund that workers can use as they like. Such flexibility could ensure worker protection while respecting the fact that more than 60 percent of those surveyed work in a traditional job or are students, and that fewer than 20 percent of the workers surveyed earn half or more of their income from platform work.

The shift from traditional work to platform work in the U.S. has reached the point of no return, with more than one-in-six U.S. workers in this sector. This has been a very positive development for workers who value flexibility in their work schedules. But it has come with a cost of eroding the protection of employee benefits, which can have negative implications for workers and society. A flexible benefits fund that is made available across multiple platforms could expand the protection provided by employee benefits while delivering value to platform workers. 


\section{References}

Chen, M. Keith and Peter E. Rossi, Judith A. Chevalier and Emily Oehlsen (2019). "The Value of Flexible Work: Evidence from Uber Drivers," Journal of Political Economy, 127, p. 2735-94.

Gruber, Jonathan (2001). "Health Insurance and the Labor Market," in Joseph Newhouse and Anthony Culyer, eds., The Handbook of Health Economics. Amsterdam: North Holland, p. 645-706.

Gruber, Jonathan (2008). "Covering the Uninsured in the United States," Journal of Economic Literature, 46, p. 571-606.

Gruber, Jonathan (2016). "Expanding Financial Security for Workers in the New Economy," Aspen Institute Future of Work Initiative, August 2016, https://www.aspeninstitute.org/publications/gruber/.

Thaler, Richard and Shlomo Benartzi (2004). "Save More Tomorrow: Using Behavioral Economics to Increase Employee Savings," Journal of Political Economy, 112, p. S164S187. 


\section{Figures and Tables}

Figure 1. Distribution of Drivers Across Services in the Last 12 Months

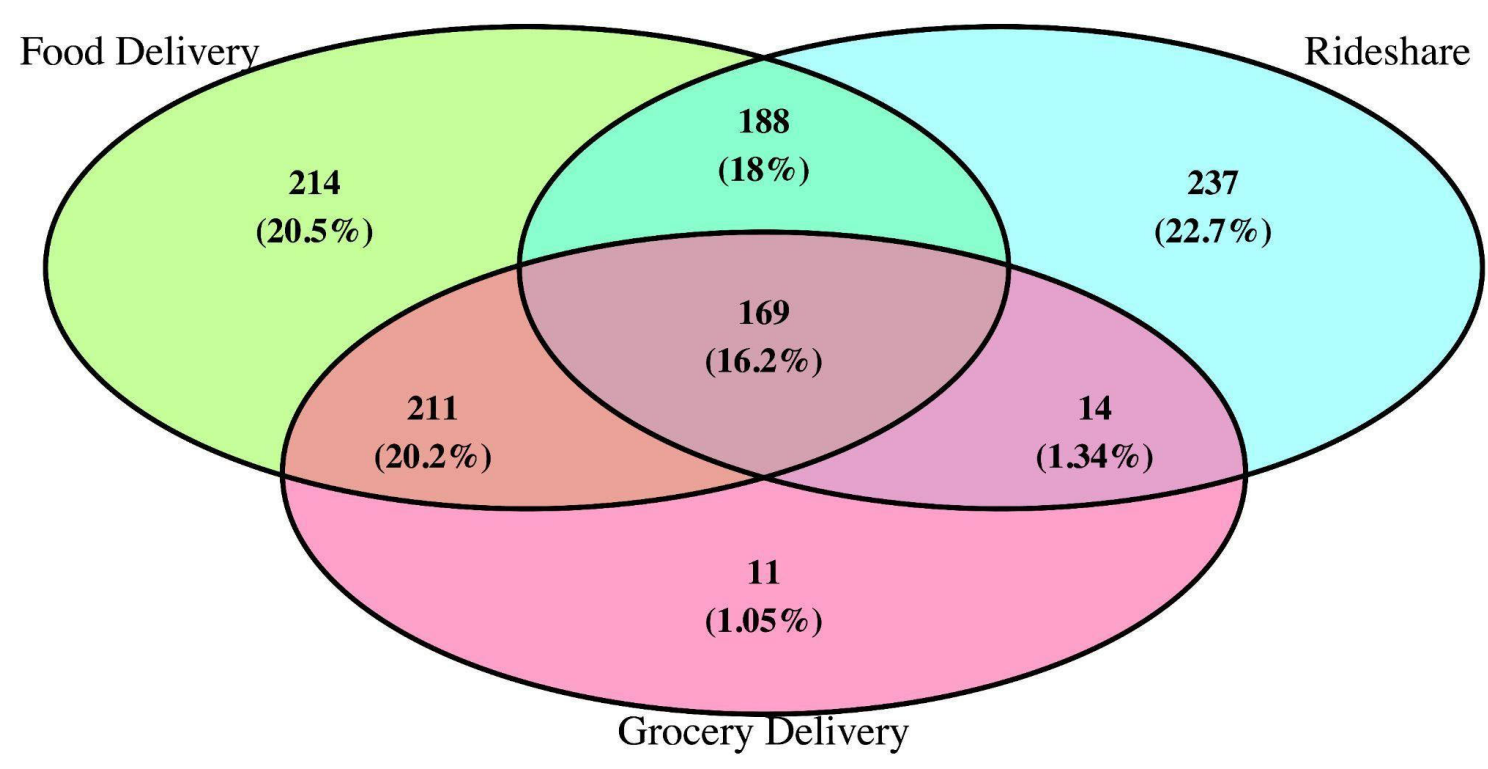

Figure 2. How Many Platforms Have Drivers Ever Worked with Besides Uber?

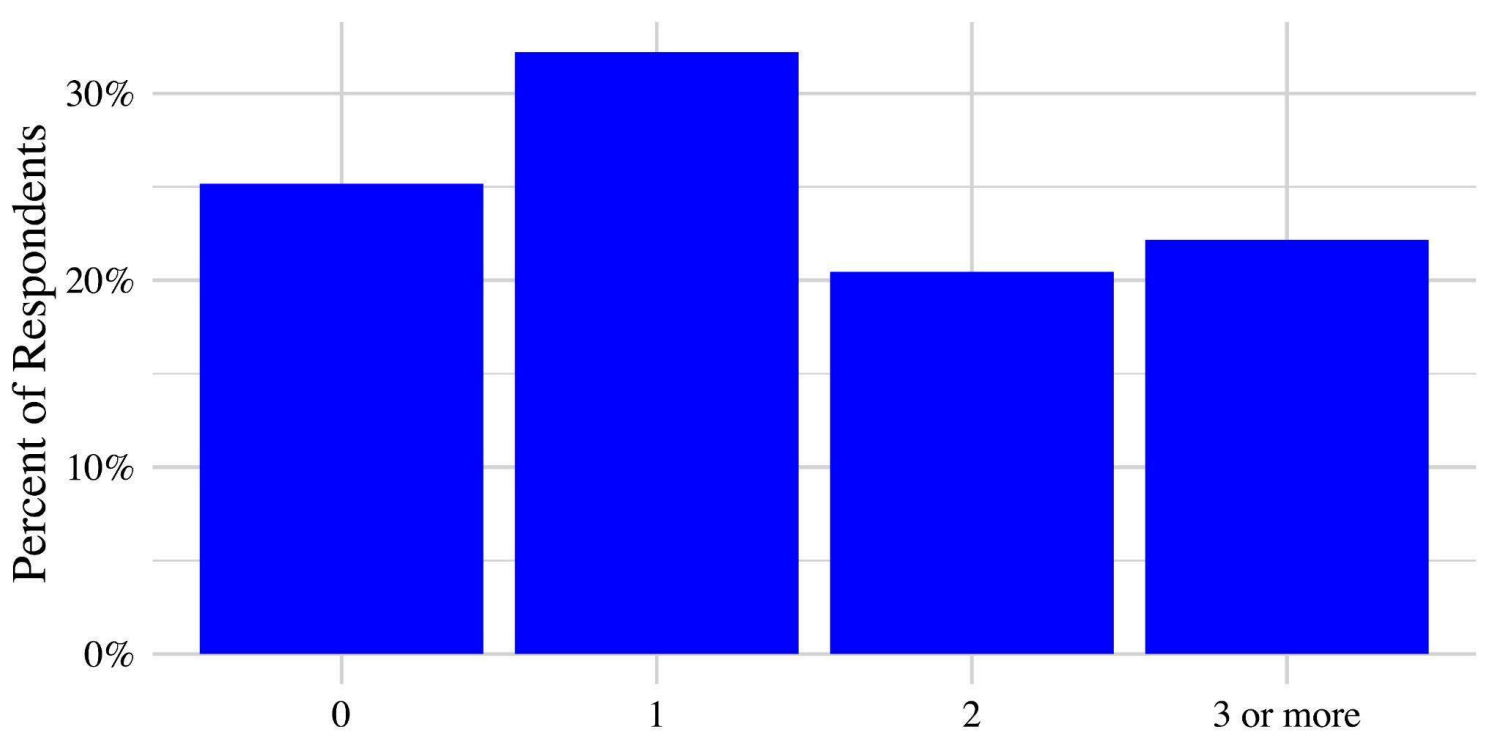


Figure 3. Annual Income from All Rideshare and Delivery Platforms

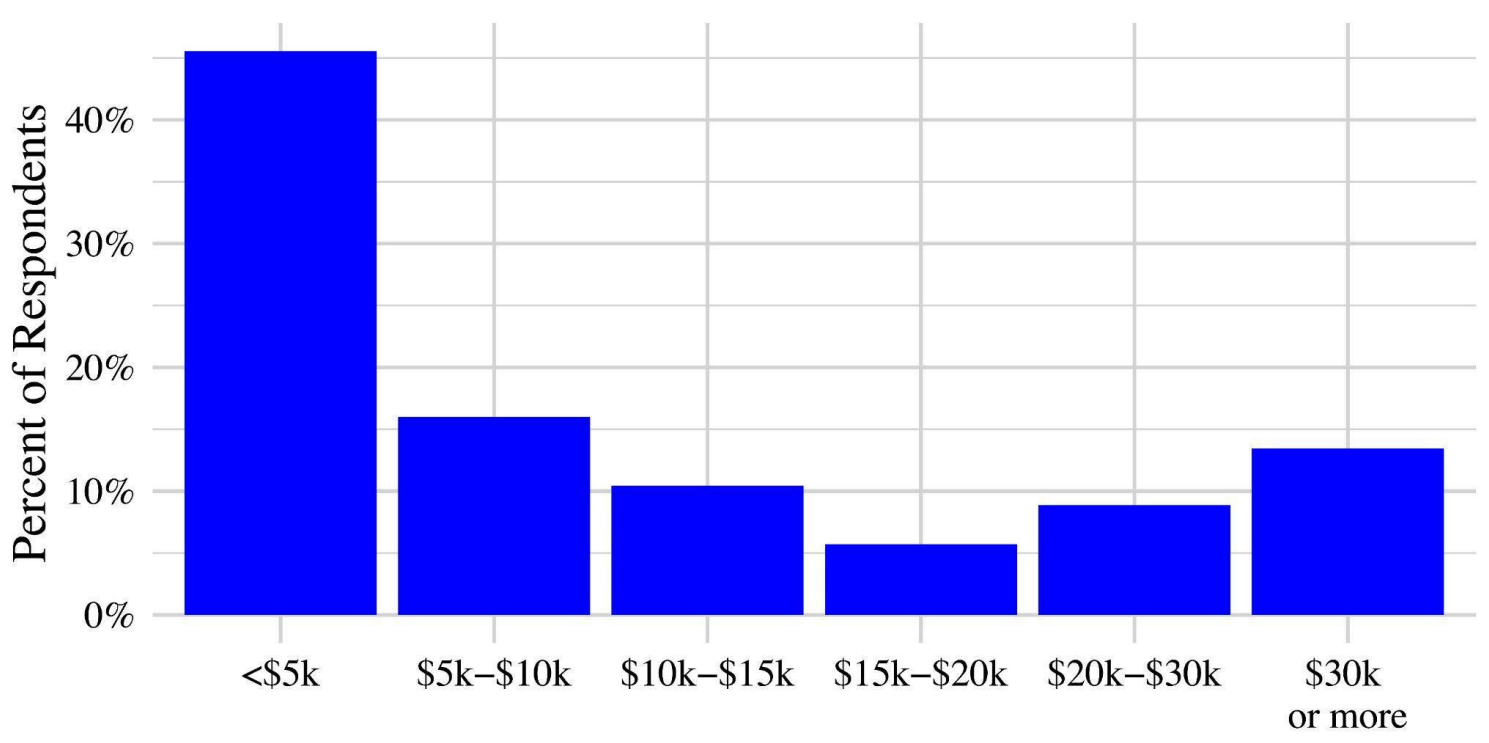

Figure 4. App Usage and Earnings in the Last 12 Months

Thinking about your total earnings from all ridesharing/food delivery work, which of the following best describes you?

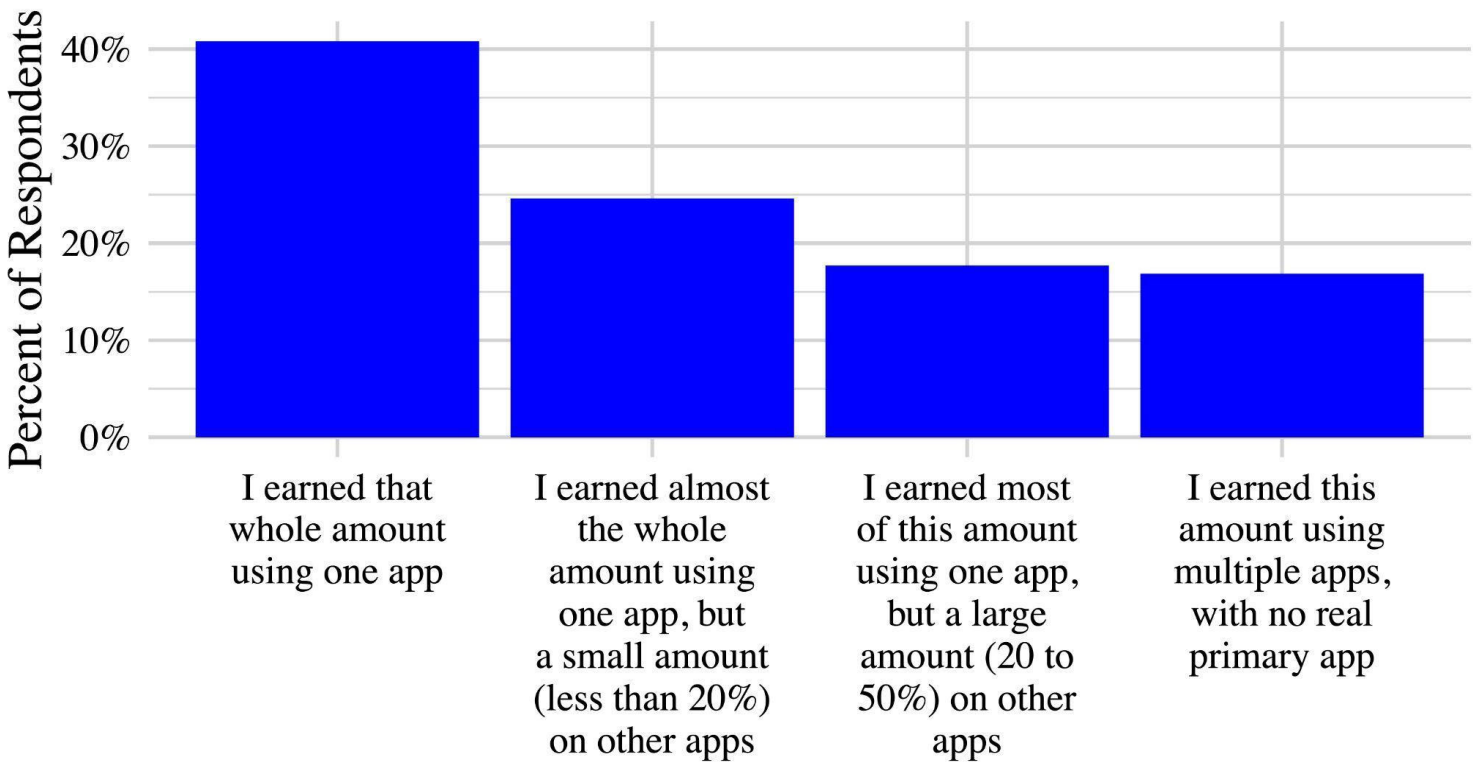


Figure 5. Personal Income of Respondents

Distribution of earnings in the last 12 month, excluding platform work

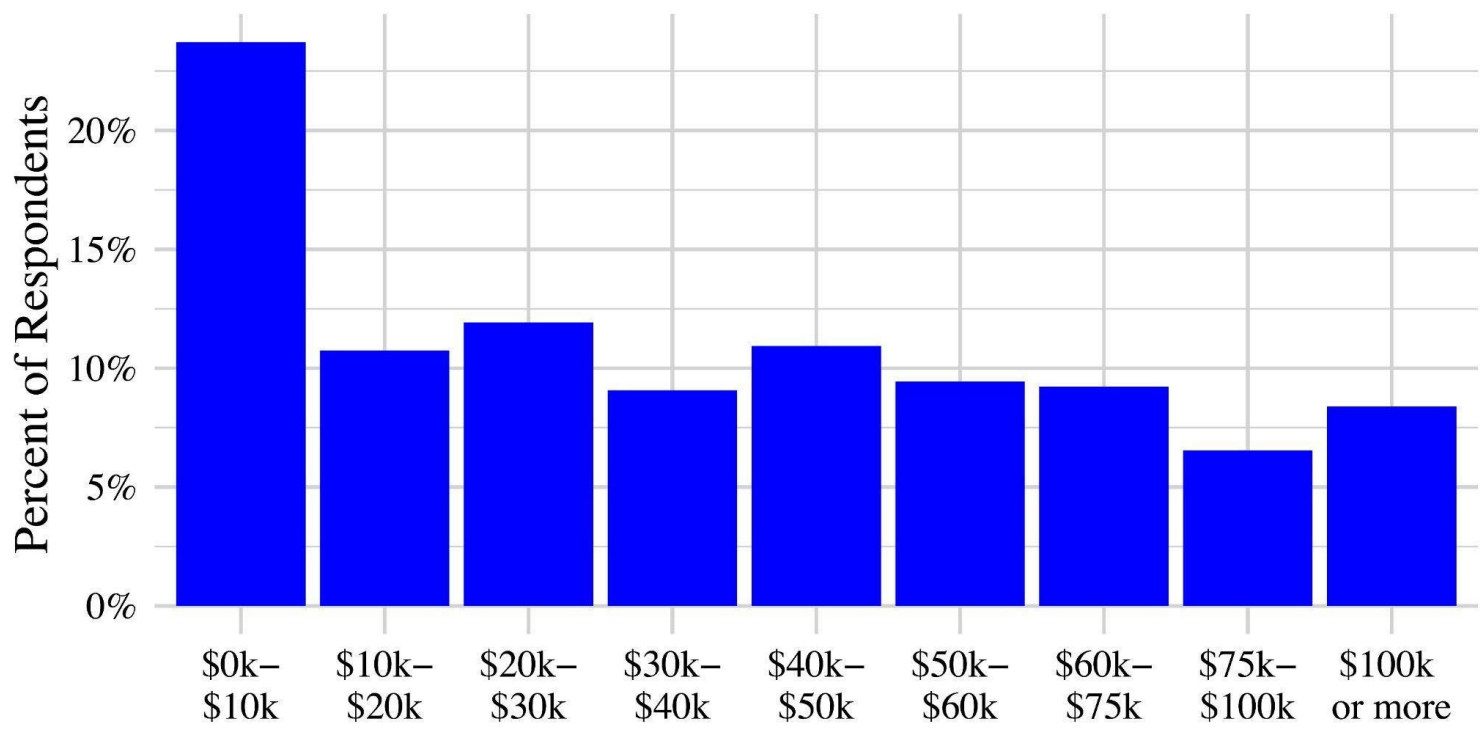

Notes. This figure includes only respondents who said they worked at another part-time or full-time traditional job, were running their own business or performed other gig or freelance work that was not app-based rideshare or food delivery.

Figure 6. Household Income of Drivers and Couriers

(a) Distribution of household income for the last 12 months

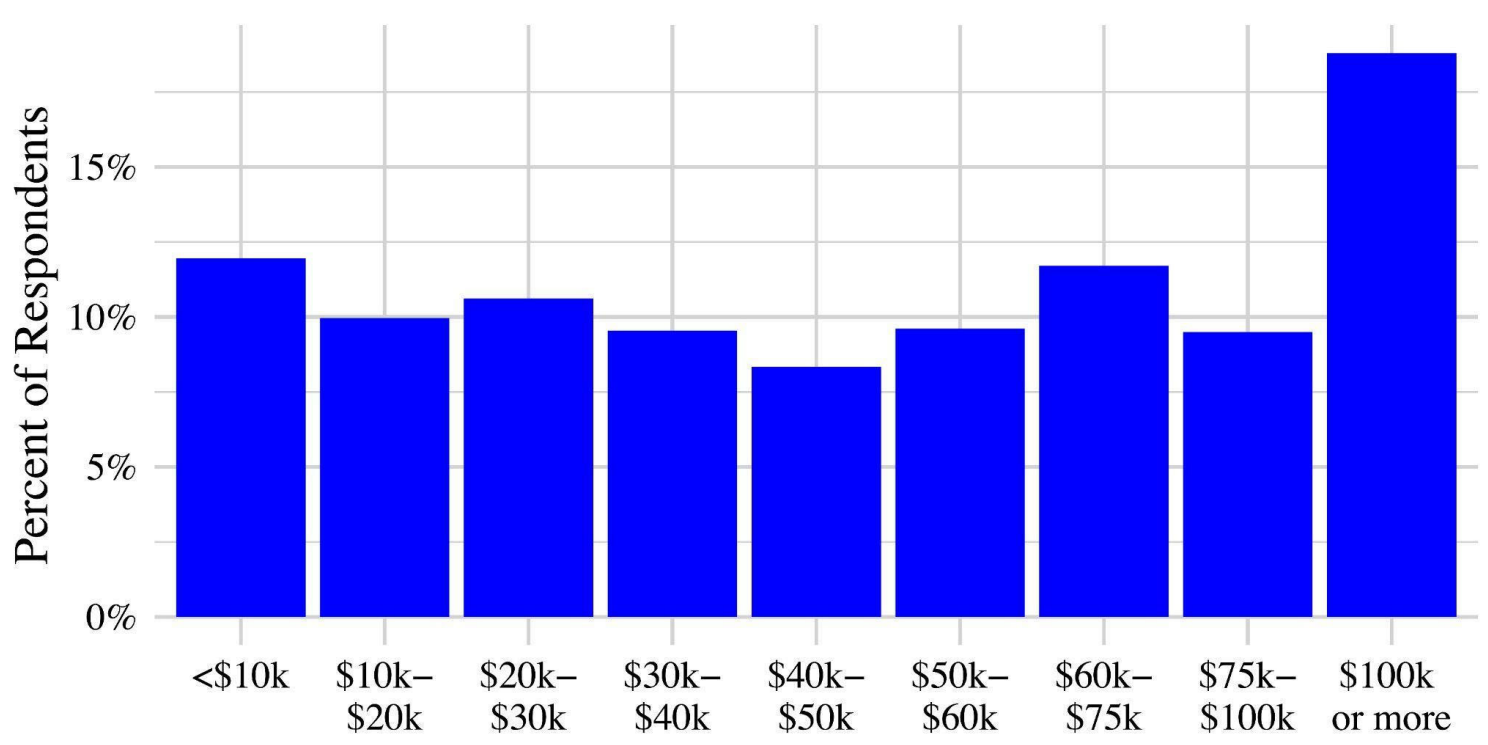


(b) Distribution of household income as percent of the poverty threshold

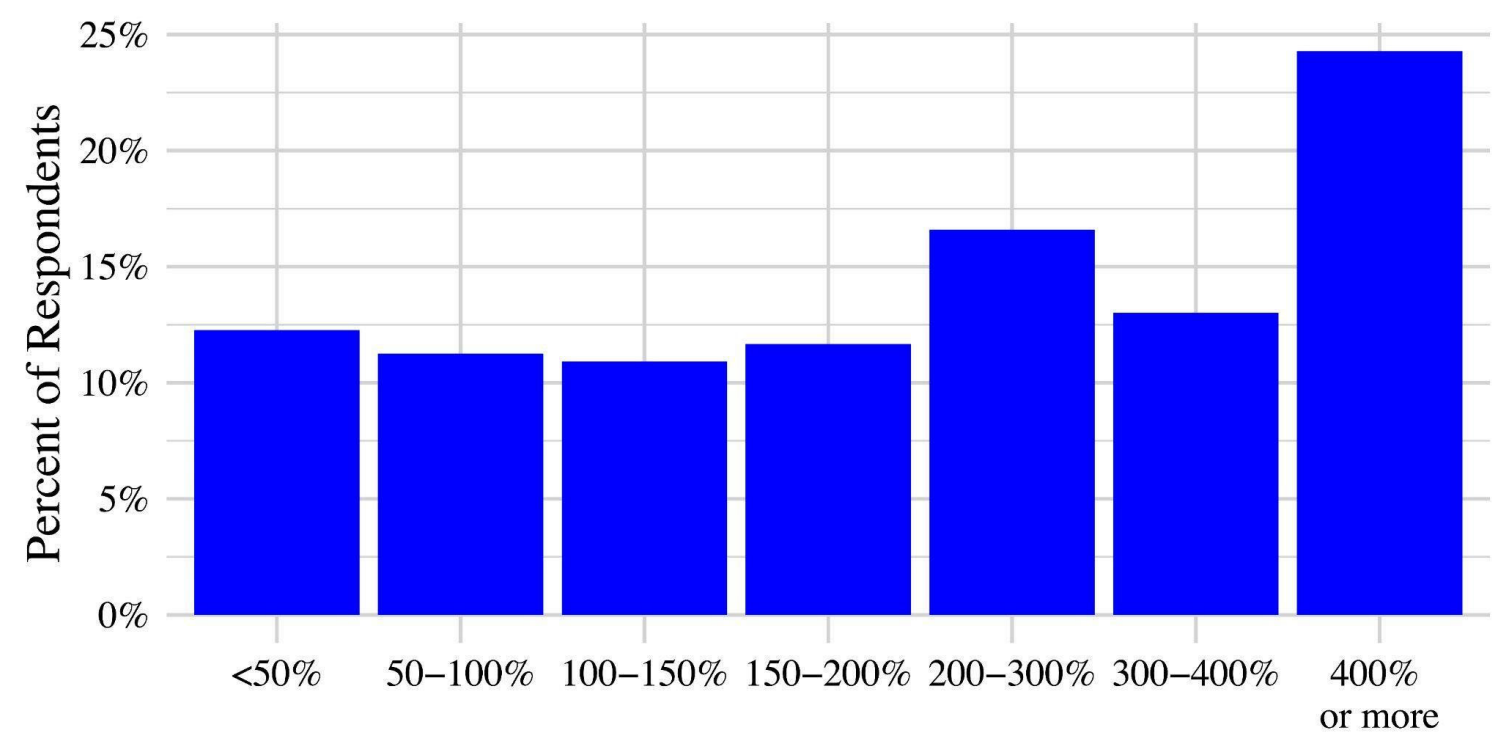

(c) Distribution of income from apps as a share of household income

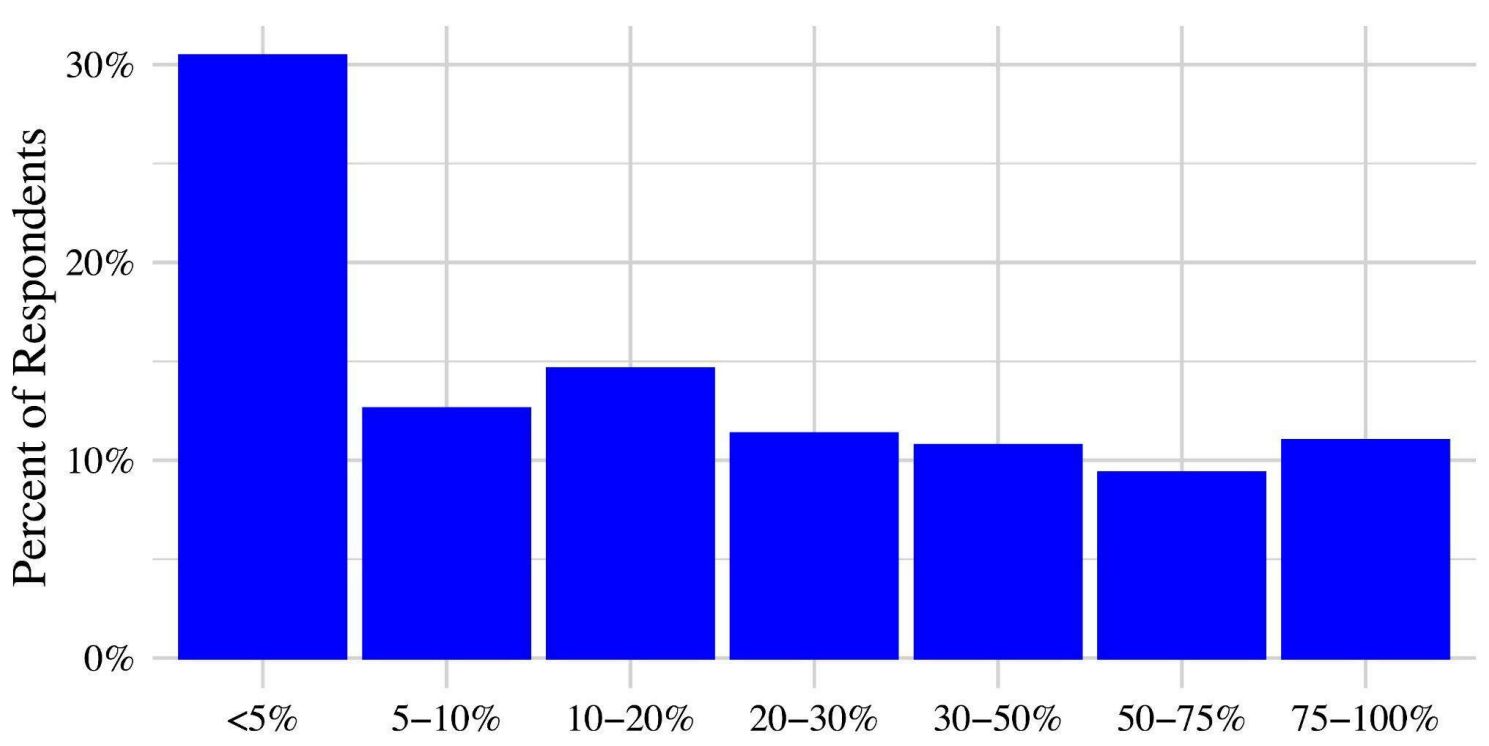

Notes. These figures include all respondents - those who had other work in the last 12 month and those who did not. Poverty threshold data is from the Census Bureau, available at https://www.census.gov/data/tables/time-series/demo/income-poverty/historical-poverty-thresholds.html. 
Figure 7. Available Savings

Percent of respondents who could cover an emergency expense using cash, savings or a credit card that they would pay off fully at the next statement.

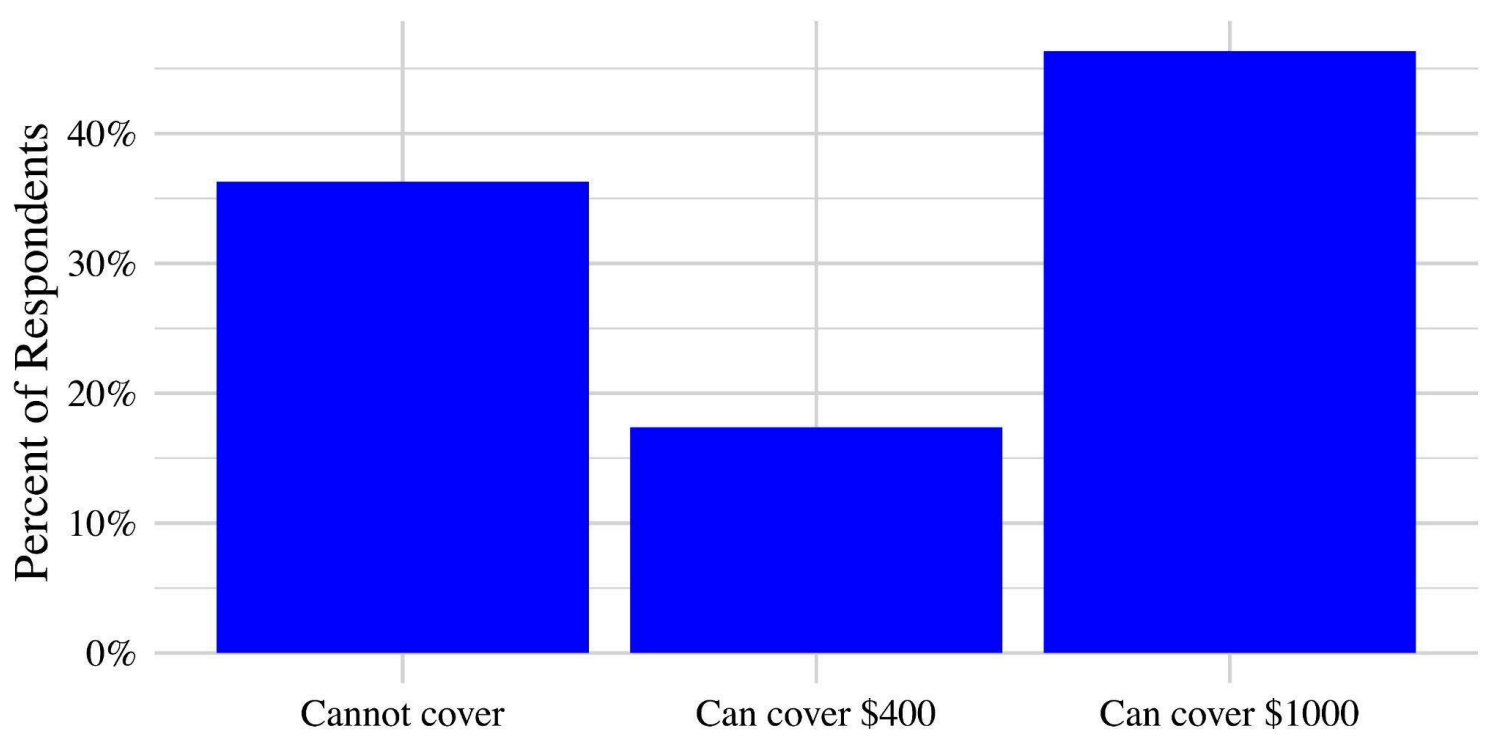


Figure 8. Cash Valuation of Benefits

(a) Percent of respondents who prefer $\$ \mathrm{X}$ in cash to $\$ 1$ in benefits

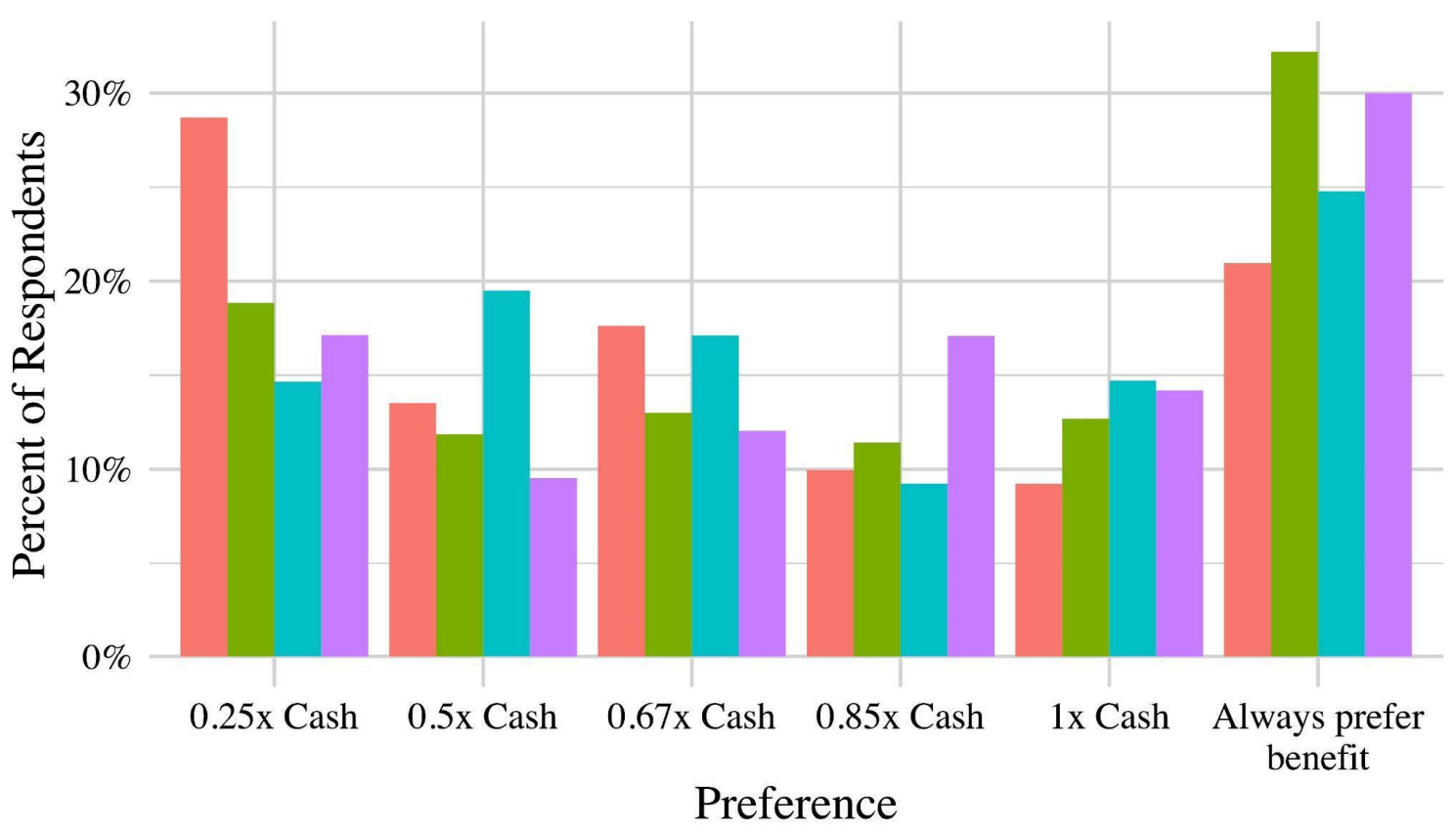

Benefits Health Retirement $\quad$ Sick leave $\quad$ Flexible 
(b) Percent of respondents who prefer $\$ X$ in cash to $\$ 1$ in benefits: respondents with another full-time job

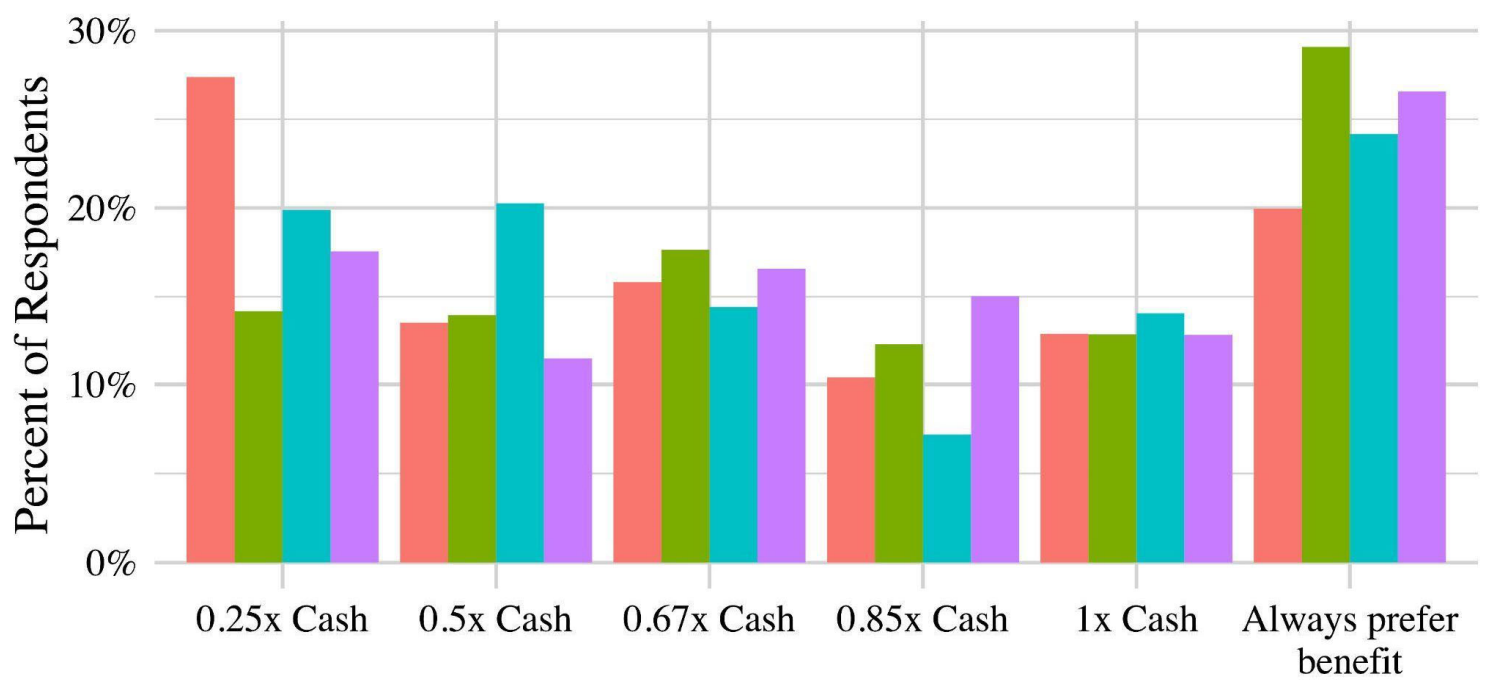

(c) Percent of respondents who prefer $\$ X$ in cash to $\$ 1$ in benefits: respondents without another full-time job

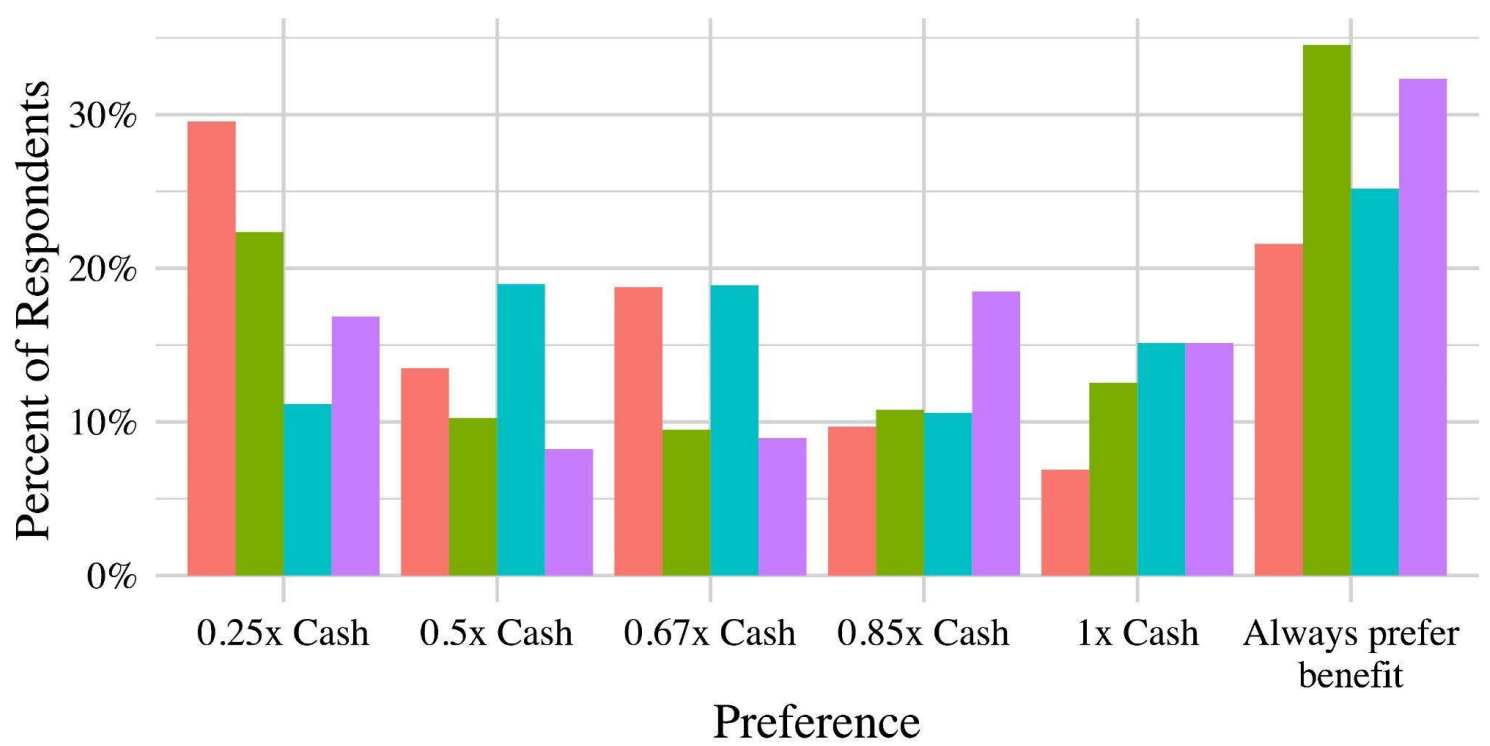

Benefits Health Retirement $\quad$ Sick leave $\quad$ Flexible 
(d) Percent of respondents who prefer $\$ \mathrm{X}$ in cash to $\$ 1$ in benefits: respondents without health insurance

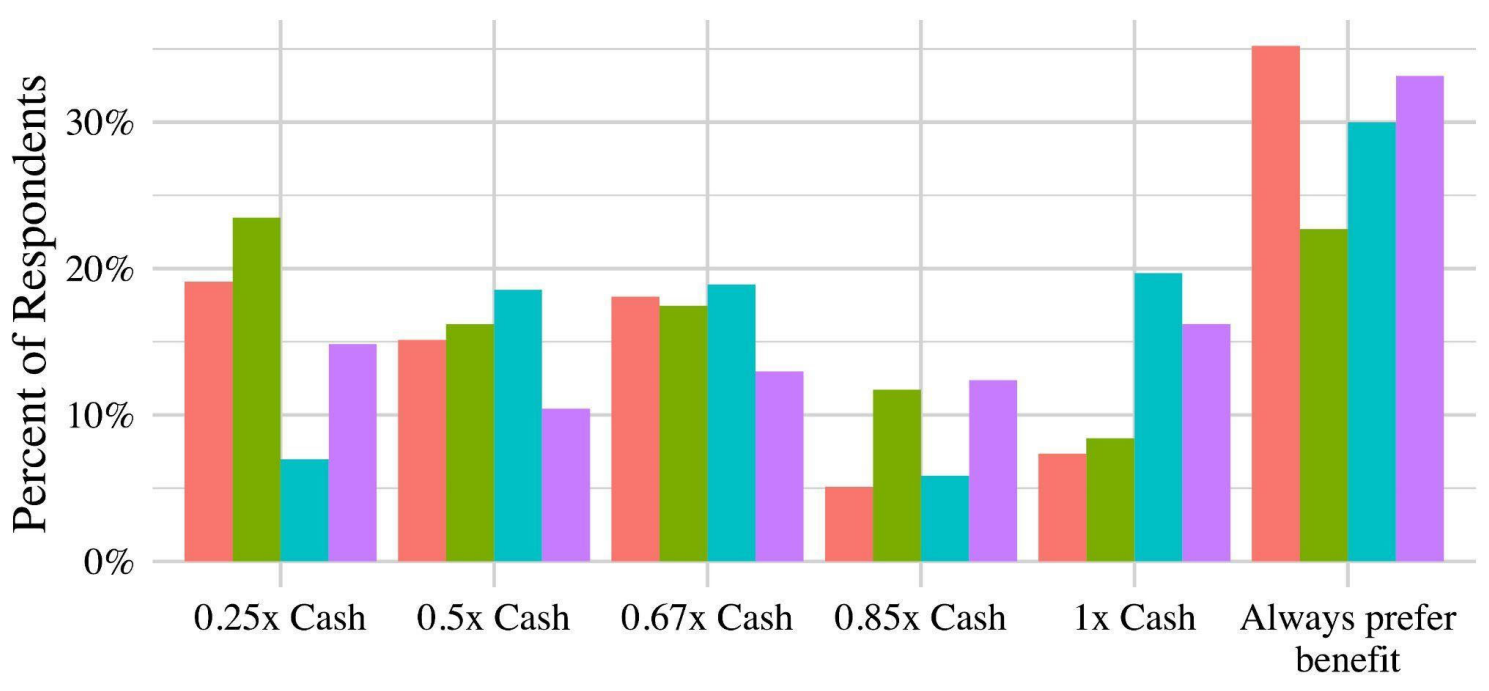

(e) Percent of respondents who prefer $\$ \mathrm{X}$ in cash to $\$ 1$ in benefits: respondents without a retirement savings account

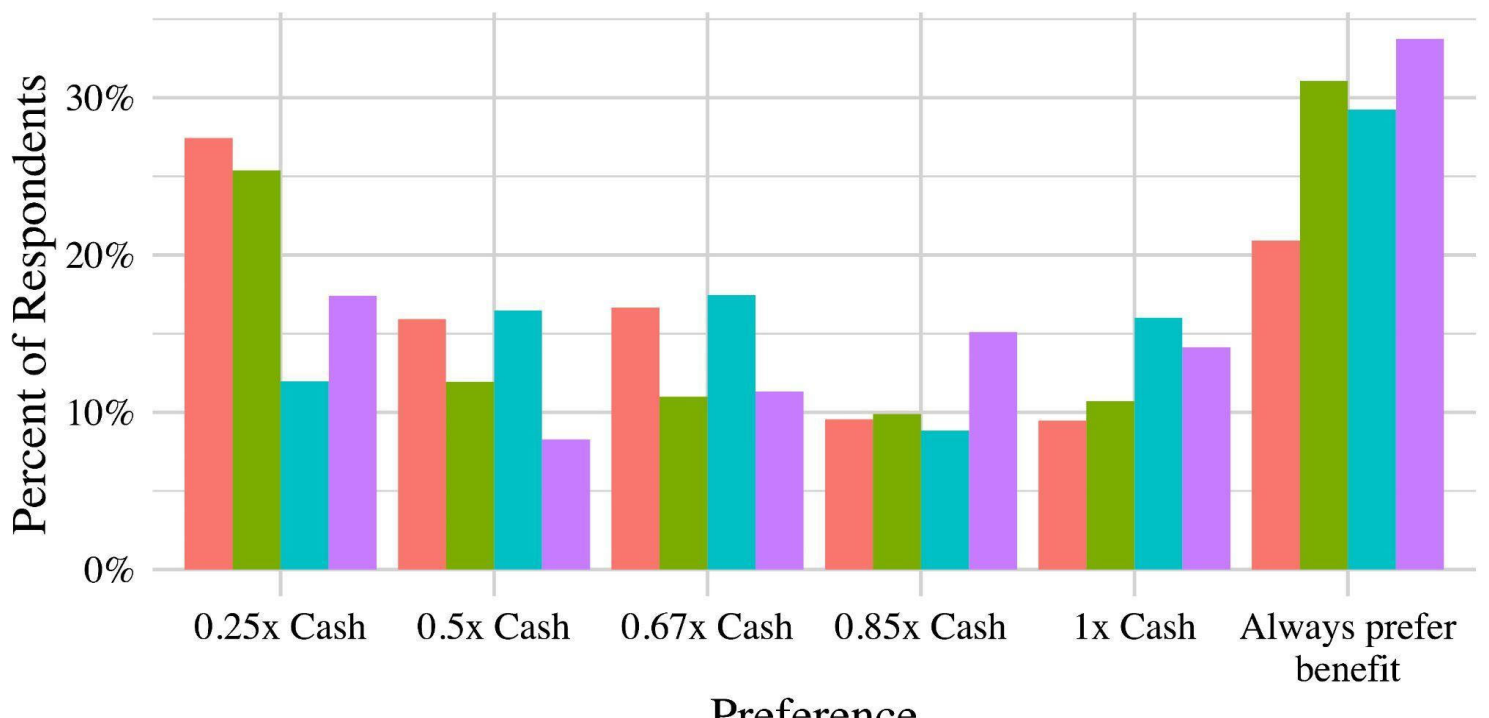

Benefits $\quad$ Health $\square$ Retirement $\square$ Sick leave $\square$ Flexible

Notes. This figure provides the distribution of respondents by the upper bound of the cash valuation. For example, people labeled 'prefer $85 \mathrm{x}$ Cash' will take at least 0.67 to 0.85 dollars of cash for each dollar of benefits. 
Figure 9. Accounting for Differences in Tax Obligations for Cash and for Benefits

\section{Panel A. All respondents}

(a) Upper bound of benefits valuation

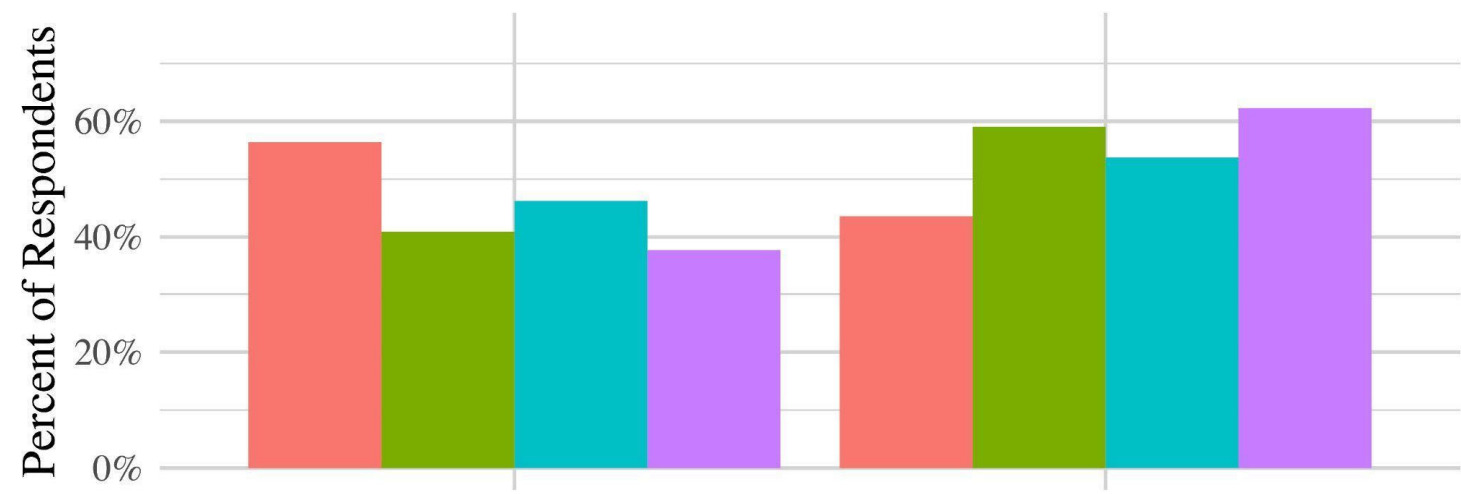

Benefit worth less than cash

Benefit worth more than cash

(b) Middle of benefits valuation range

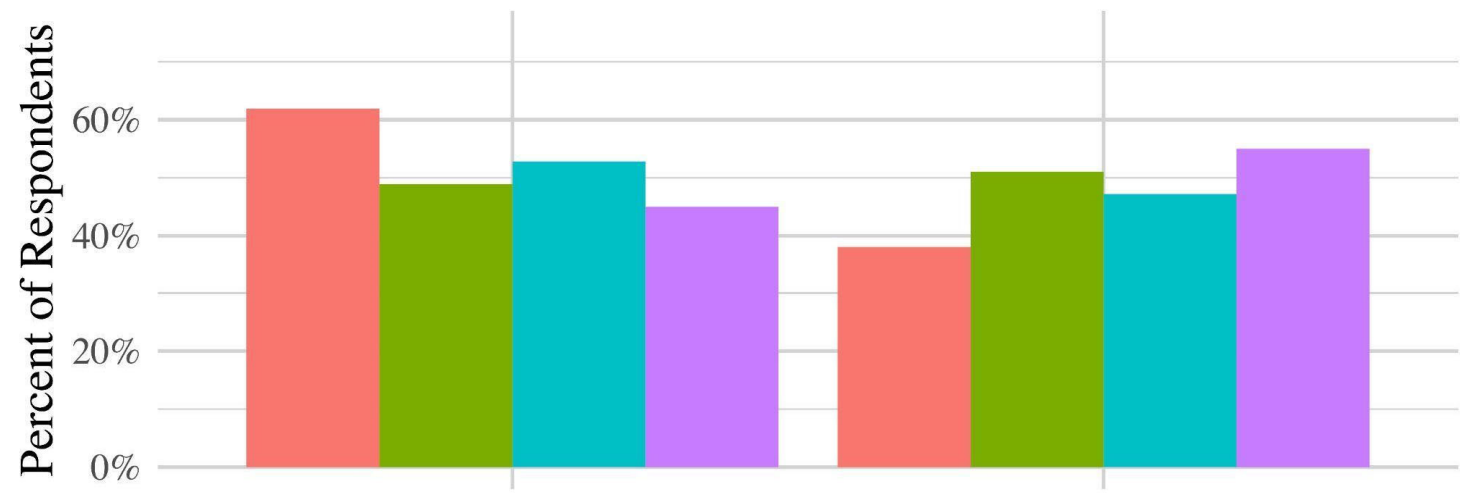

Benefit worth less than cash

Benefit worth more than cash

(c) Lower bound of benefits valuation

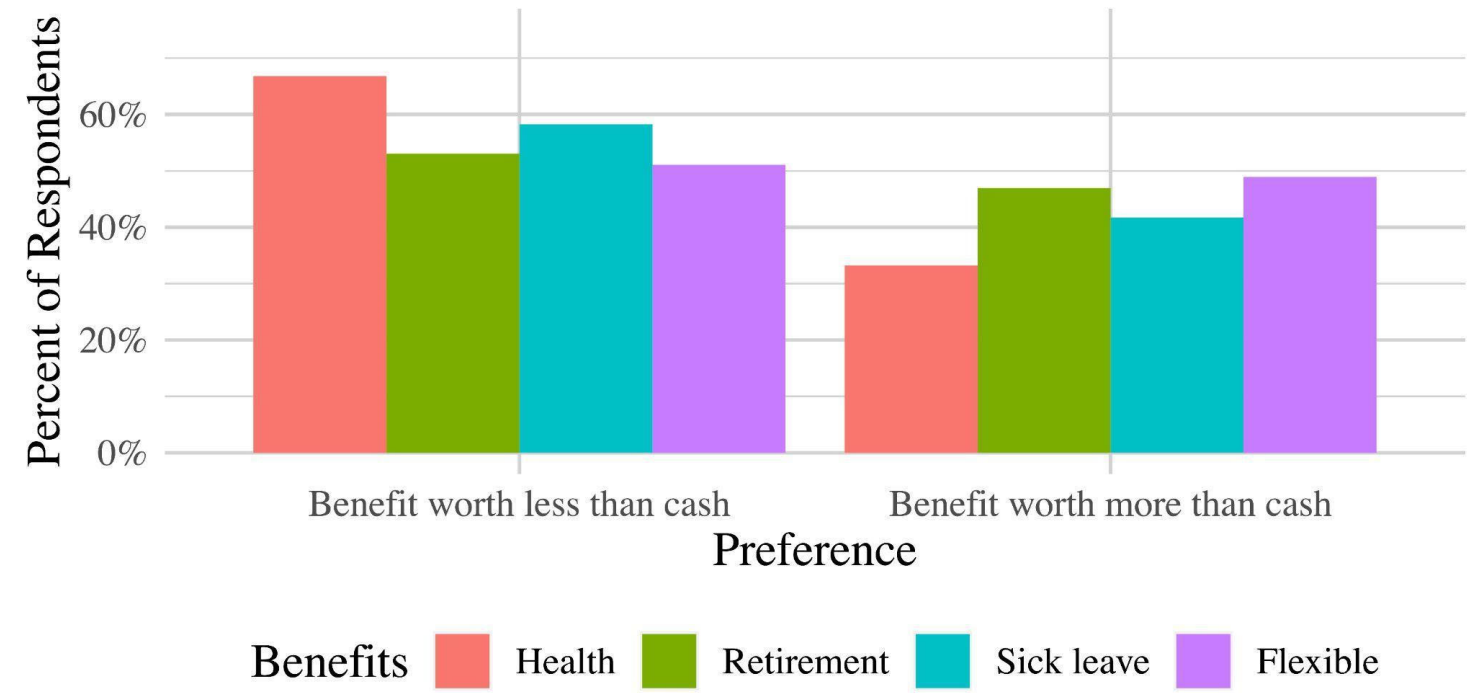


Panel B. Upper bound of benefits valuation by subgroup

(a) Respondents without health insurance

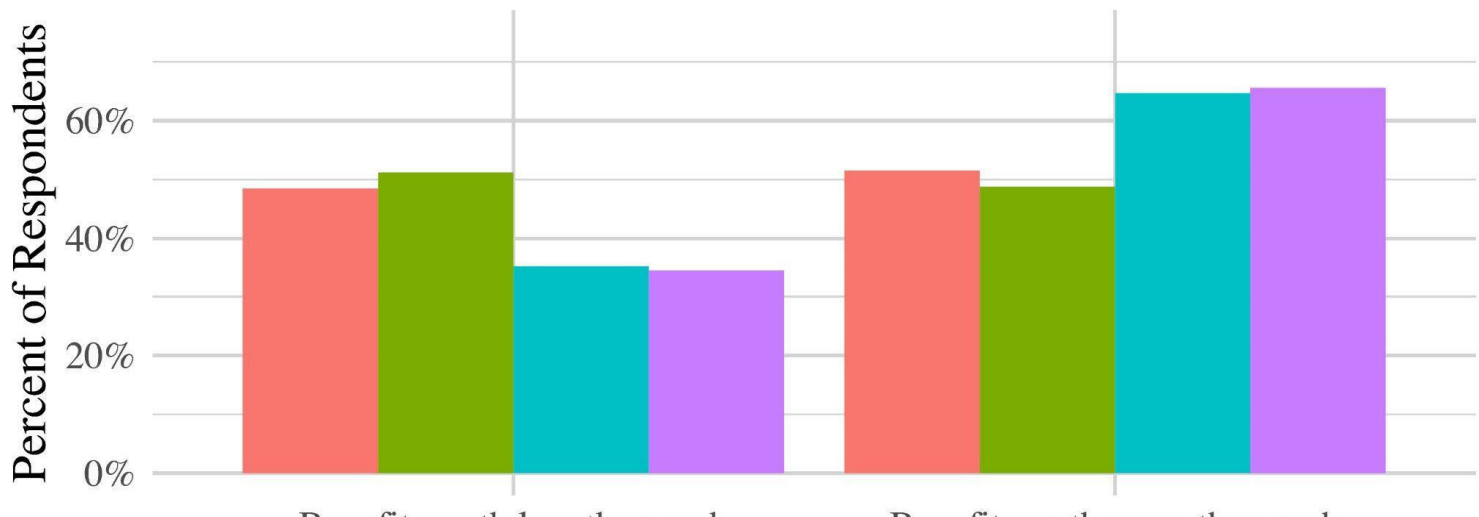

Benefit worth less than cash $\quad$ Benefit worth more than cash

(b) Respondents without a retirement savings account

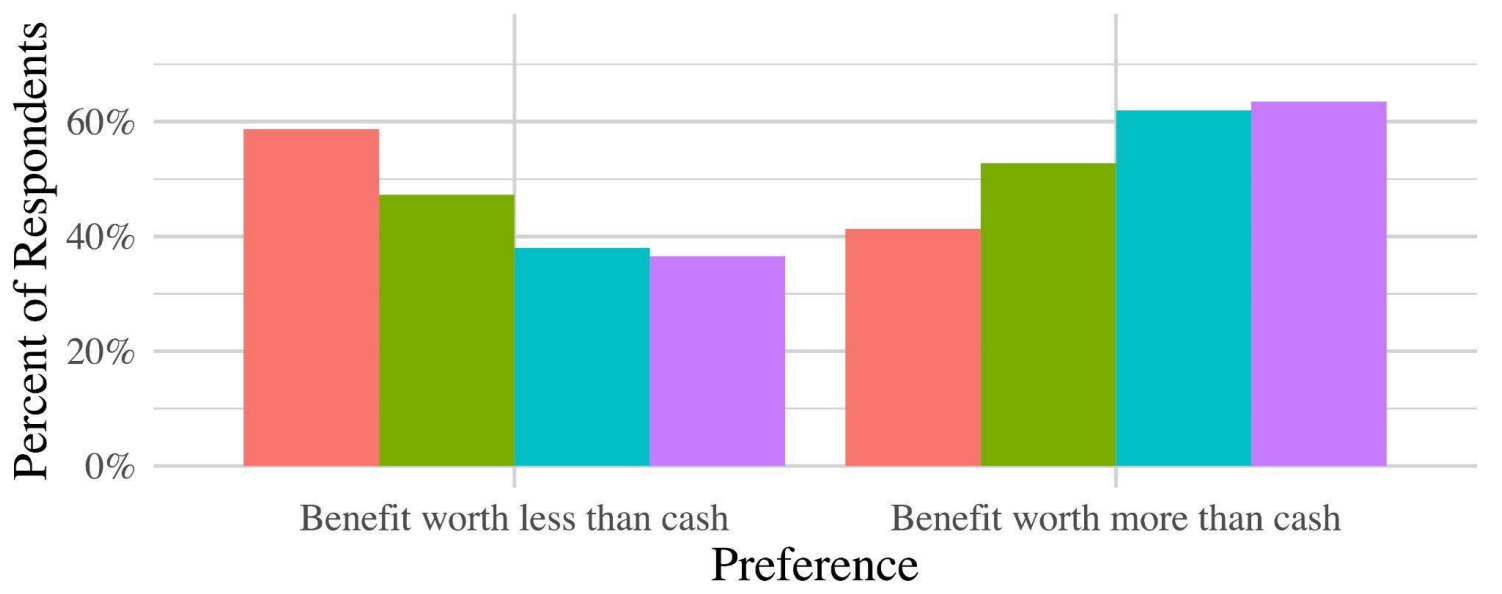

Benefits Health $\square$ Retirement $\square$ Sick leave $\square$ Flexible

Notes. These figures account for the tax favoritism shown to many employee benefits. Marginal tax rate (MTR) is calculated using the NBER TAXSIM, available at: http://taxsim.nber.org/taxsim32/. The survey allows me to identify respondents who will take, for example, between $\$ 0.67$ and $\$ 0.85$ of cash for each dollar of benefits. I then calculate the pre-tax cash range, $0.67 /(1-\mathrm{MTR})$ to $0.85 /(1-\mathrm{MTR})$ per dollar of benefit. Panel A (a) reports the cash valuation of benefits based on the upper bound of that range, (b) is based on the middle of the interval and (c) is based on the lower bound. 
Figure 10. Ranking on Benefits

(a) All respondents

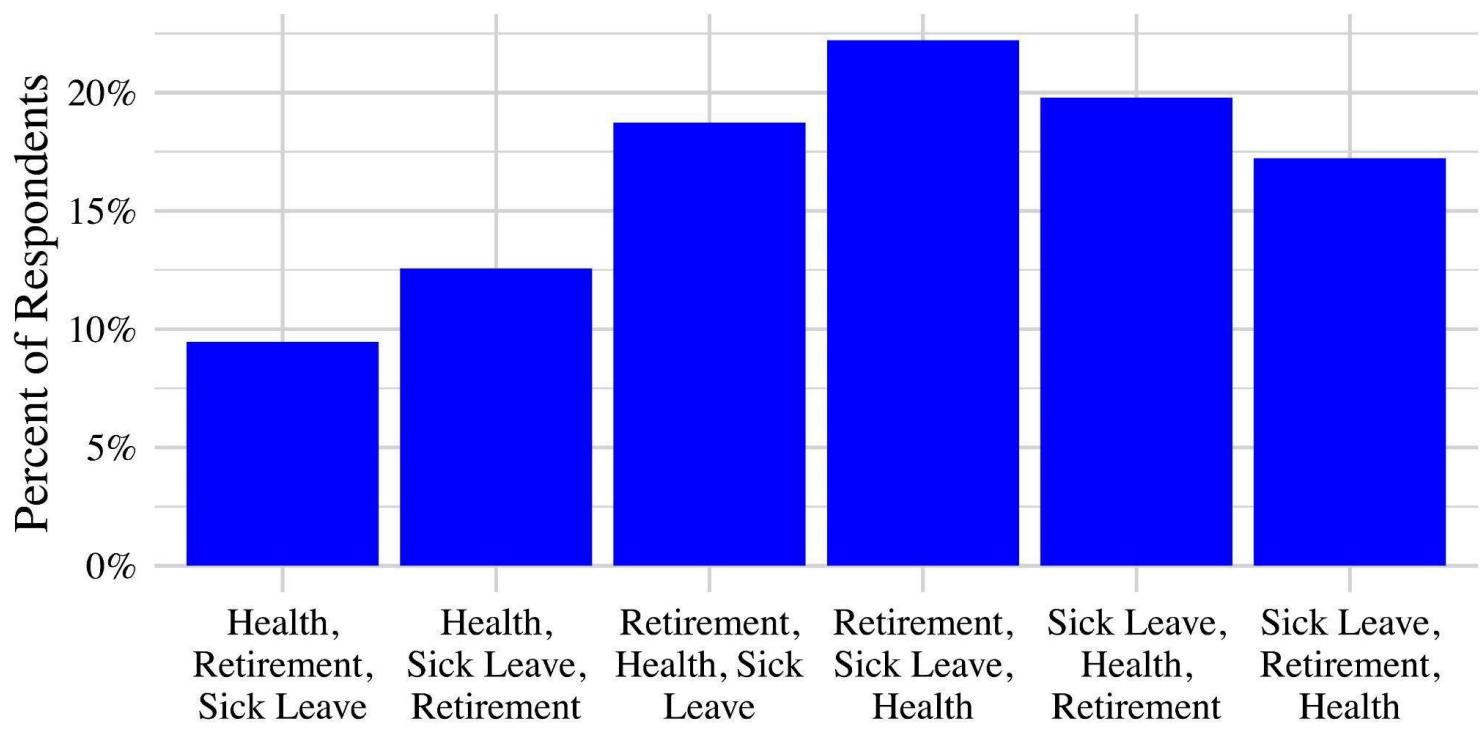

(b) Respondents with another full-time job
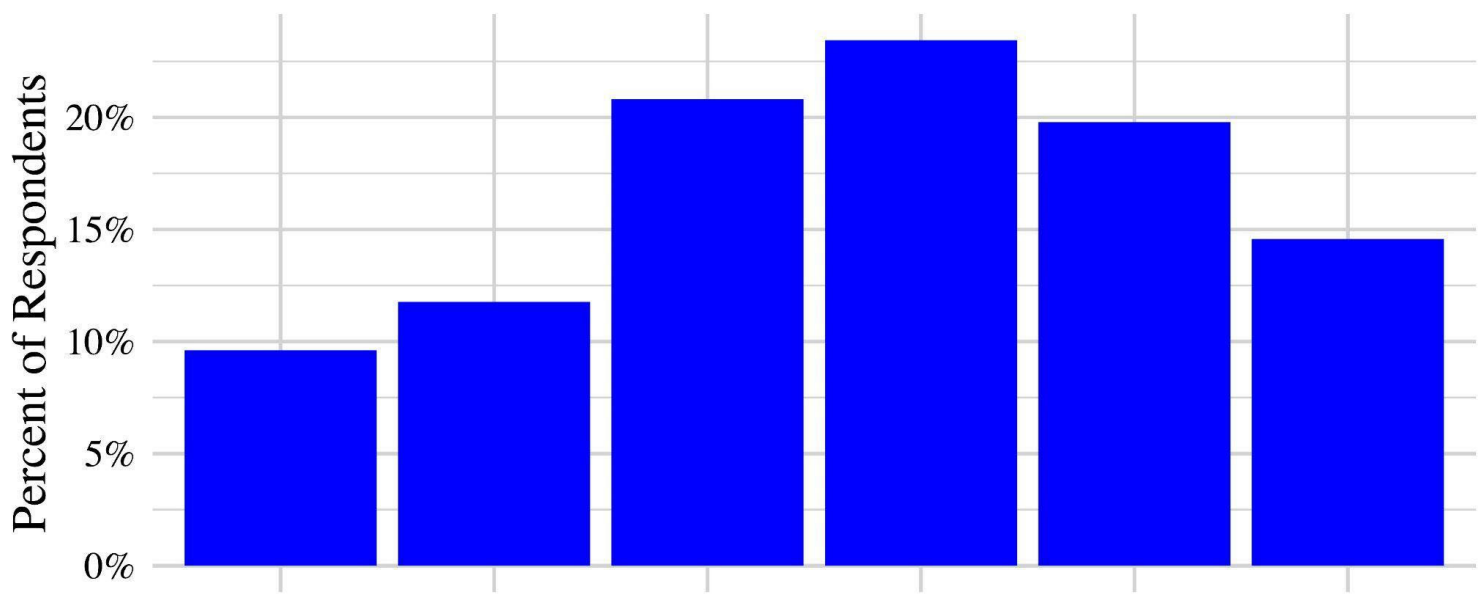

Health, Health, Retirement, Retirement, Sick Leave, Sick Leave, Retirement, Sick Leave, Health, Sick Sick Leave, Health, Retirement, Sick Leave Retirement Leave Health Retirement Health 
(c) Respondents without another full-time job

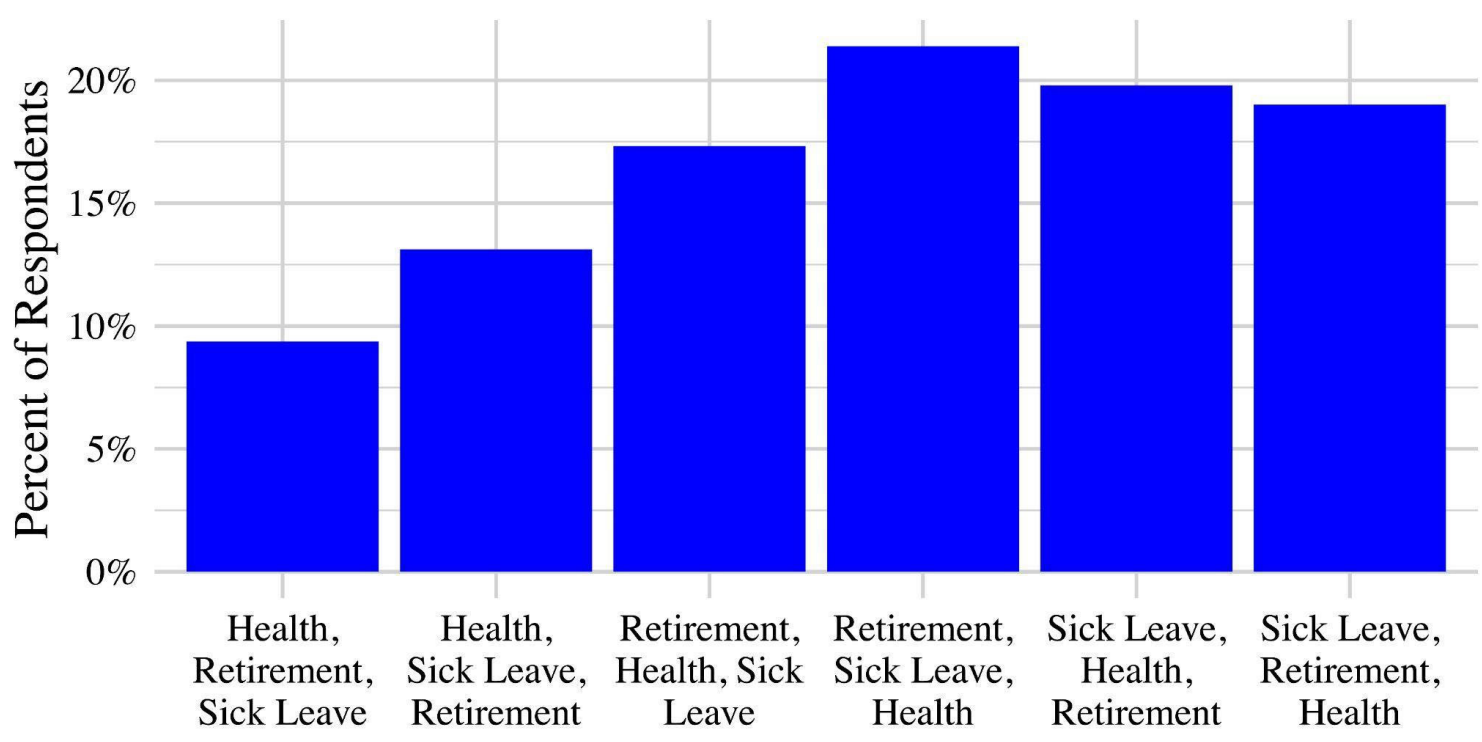

(d) Respondents without health insurance

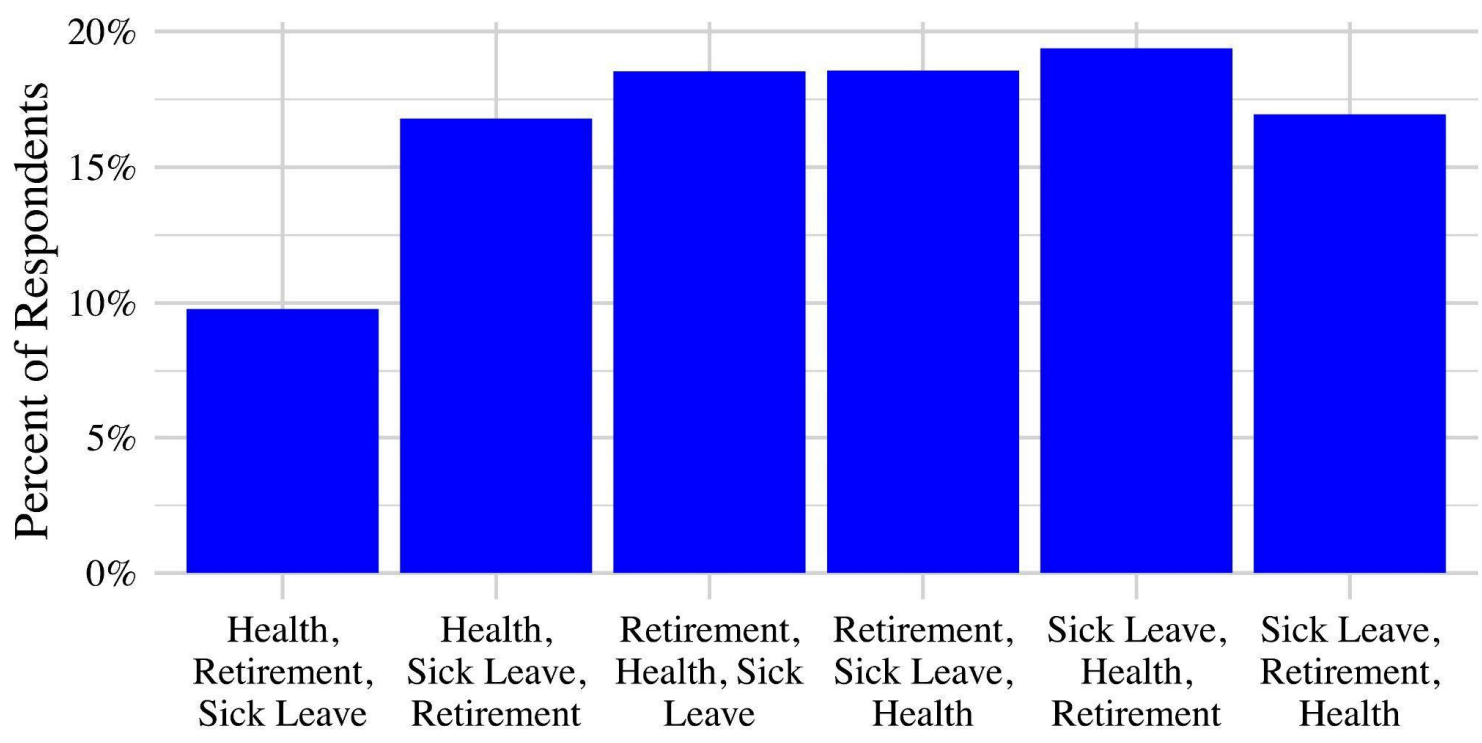


(e) Respondents without a retirement savings account

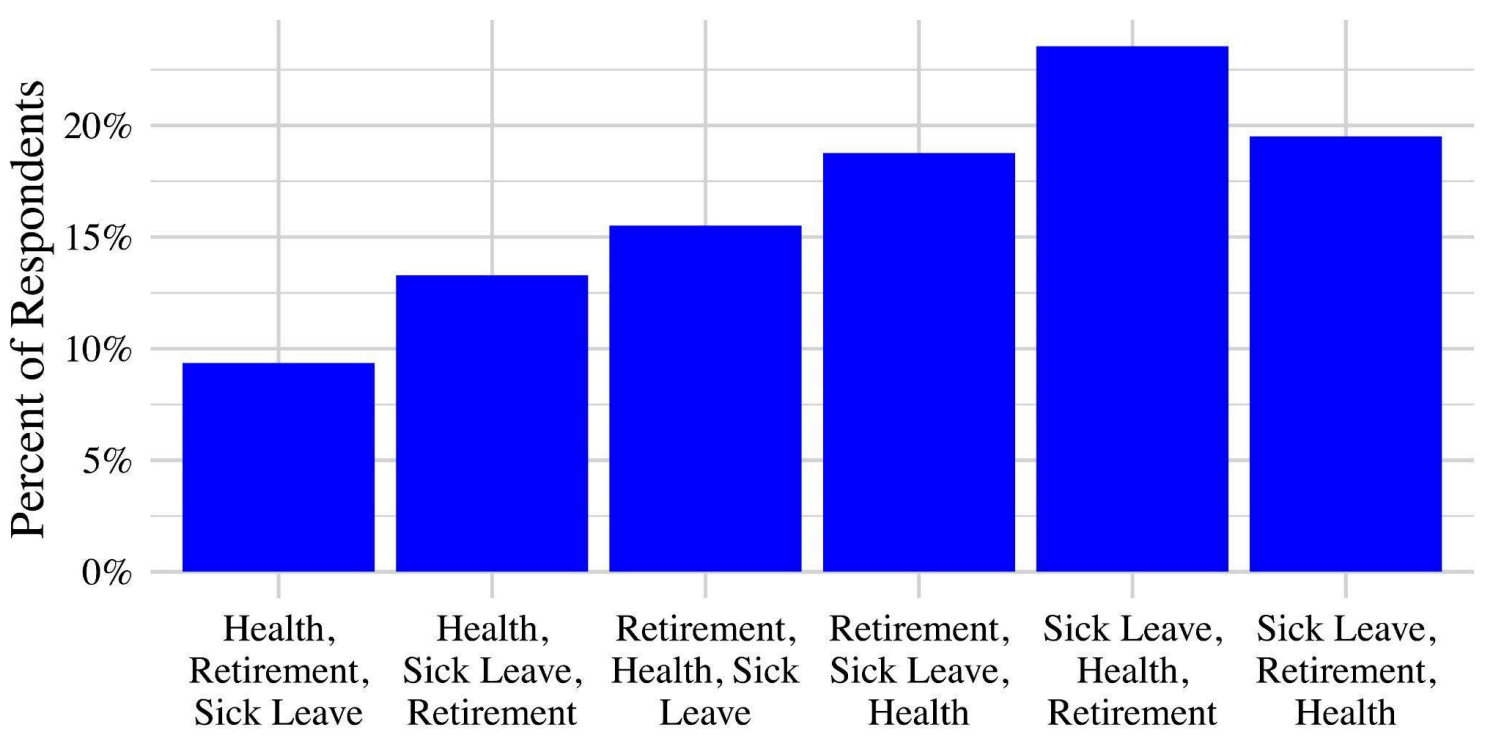

Notes. These figures report the percent of respondents who choose each configuration of benefit rankings. For example, the first bar shows the percent of respondents ranking health care benefits first, retirement benefits second, sick and family leave third. 
Figure 11. Do Respondents Prefer Flexible or Inflexible Benefits?

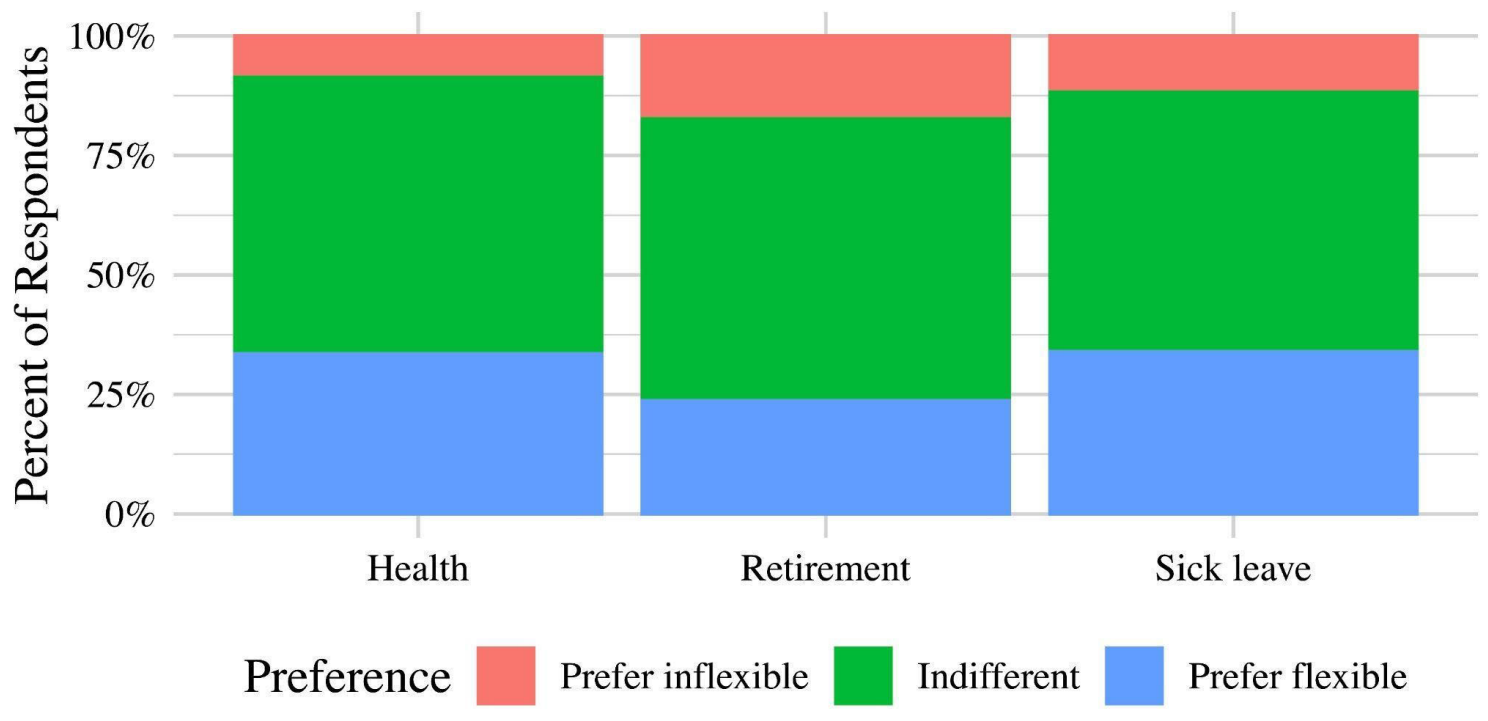

Figure 12. What Do Respondents Want to Do with Unused Funds in a Flexible Benefits Account?

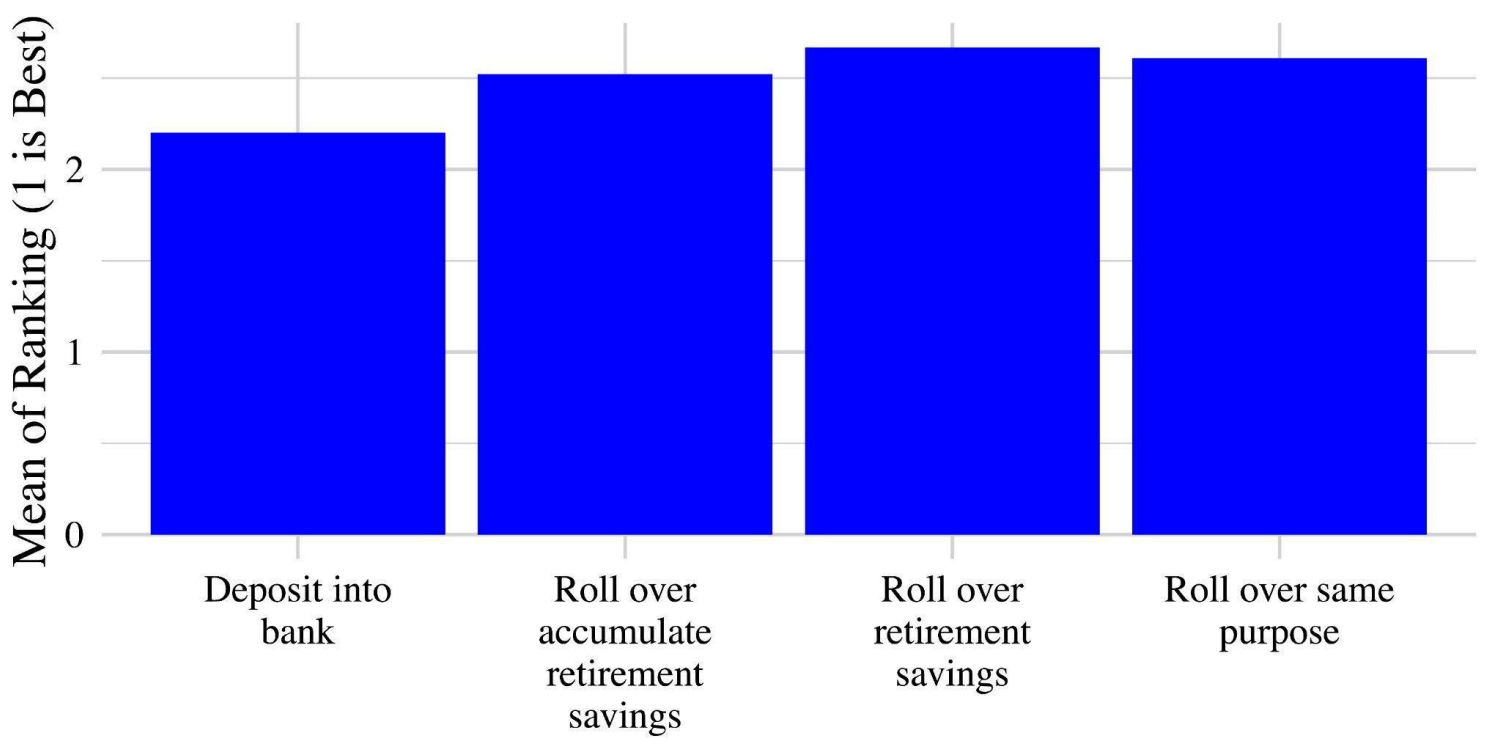


Table 1. Demographic Characteristics of Respondents and the U.S. Civilian Labor Force.

Uber

Age

$<25$

$25-54$

$55-64$

$65+$

Female

Non-Hispanic White

Black

Hispanic

Asian

Other/Multiple races selected

Did not answer
$11.1 \%$

$76.3 \%$

$10.2 \%$

$2.4 \%$

$\underline{\text { Gender }}$

$30.1 \%$

$\underline{\text { Race and ethnicity }}$

$\begin{array}{rr}51.0 \% & 61.4 \% \\ 17.9 \% & 11.7 \% \\ 13.1 \% & 18.0 \% \\ 5.7 \% & 6.2 \% \\ 8.8 \% & 2.6 \% \\ 3.5 \% & \end{array}$

\section{Household composition}

Married, no children

$16.6 \%$

Married, with children

$25.0 \%$

Other, no children

$40.0 \%$

Other, with children
$47.0 \%$

U.S.

$12.6 \%$

$63.8 \%$

$17.0 \%$

$6.6 \%$

$6.2 \%$

$.6 \%$ 
Table 1. (continued).

Uber

U.S.

\section{Number of children (conditional on having children)}
One
$45.4 \%$
Two
$32.1 \%$
Three
$15.2 \%$
Four or more
$7.4 \%$

\section{Caregiving to a family member}

Yes

$43.5 \%$

\section{Education}

High school dropout or diploma

$21.3 \%$

$31.1 \%$

only

Technical degree or some

$40.7 \%$

$25.9 \%$

college

4-year college degree

$23.7 \%$

$26.6 \%$

Graduate degree

$14.3 \%$

$16.5 \%$

Note. The data on the 2020 U.S. civilian labor force characteristics are from https://www.bls.gov/. 
Table 2. Geographic Distribution of Respondents and the U.S. Civilian Labor Force.

$\begin{array}{lcr} & \text { Uber } & \text { U.S. } \\ \text { East North Central } & 15.7 \% & 4.9 \% \\ \text { East South Central } & 3.6 \% & 12.4 \% \\ \text { Middle Atlantic } & 17.4 \% & 14.4 \% \\ \text { Mountain } & 8.4 \% & 7.2 \% \\ \text { New England } & 3.9 \% & 20.0 \% \\ \text { Pacific } & 4.4 \% & 5.5 \% \\ \text { South Atlantic } & 28.2 \% & 12.1 \% \\ \text { West North Central } & 2.5 \% & 7.8 \% \\ \text { West South Central } & 15.9 \% & 15.8 \% \\ \text { Notes. The U.S. data is from https://www.bls.gov/. } & & \end{array}$


Table 3. Distribution of Respondents across Types of Gig Work Percent who have performed gig work type in past 12 months

$\begin{array}{lc}\text { Food Delivery } & 73.7 \% \\ \text { Rideshare } & 57.3 \% \\ \text { Grocery Delivery } & 38.3 \% \\ \text { Handyperson } & 2.5 \% \\ \text { Retail/selling of goods } & 9.5 \% \\ \text { Dog Walking } & 2.5 \% \\ \text { Other } & 5.2 \%\end{array}$

Table 4. Distribution of Respondents across Other Platforms Percent who have ever used each platform

Lyft

Postmates

Doordash

GrubHub

Instacart

Amazon Flex

Other food delivery service
$35.2 \%$ $26.8 \%$

$42.9 \%$

$15.4 \%$

$19.0 \%$

$11.0 \%$

$6.0 \%$ 
Table 5. What Else Do Respondents Do?

In addition to working with rideshare/delivery platforms, are you...?

Student

Full-time employment at traditional job

Part-time employment at traditional job

Gig work (not rideshare/food delivery)

Running my own business

Stay-at-home parent or caregiver

Unemployed

Retired

Only working with rideshare/food delivery platforms
$12.7 \%$

$40.3 \%$

$8.7 \%$

$7.7 \%$

$9.0 \%$

$7.2 \%$

$11.2 \%$

$5.0 \%$

$17.9 \%$ 
Table 6. Health Insurance Coverage

$\begin{array}{cc} & \text { Avg. } \\ \text { Percent } & \text { premium } \\ \text { (for insured) }\end{array}$

All respondents

Any health coverage

$76.9 \%$

$\$ 166$

Source of health coverage (for insured)

Through my employer

$36.5 \%$

$\$ 212$

Through a family member's employer

$14.9 \%$

$\$ 269$

My family or I buy it on my state's insurance

exchange (Obamacare)

$7.6 \% \quad \$ 167$

My family or I buy it from some other source

$5.9 \%$

$\$ 298$

Medicare, Medicaid, the VA or some other

government/public program

$30.6 \%$

$\$ 32$

Other

$4.6 \%$

\section{Reasons for not getting an insurance (for uninsured)}

I don't know how to get it

$10.8 \%$

I don't need it

$20.4 \%$

My employer (or a family member's employer) offers $\quad 16.3 \%$

it but it is too expensive

I could buy it on my own but it is too expensive

$65.5 \%$

Notes. The distribution of reported health insurance premiums is trimmed to exclude $1 \%$ extreme values. 
Table 7. Health Insurance Coverage for Respondents and U.S. Population by Demographic Characteristics

Uber

U.S.

$\underline{\text { Family status }}$

Married

$83.5 \%$

$91.5 \%$

Single

$72.3 \%$

$84.5 \%$

Education, 25+ years old

High school dropout or diploma

only

$72.3 \%$

$80.1 \%$

Technical degree or some

college

$74.1 \%$

$90.0 \%$

4-year college degree

$82.9 \%$

$94.1 \%$

Graduate degree

$87.0 \%$

$96.5 \%$

\section{$\underline{\text { Race and ethnicity }}$}

Non-Hispanic White

$80.1 \%$

$94.6 \%$

Black

$77.7 \%$

$89.6 \%$

Hispanic

$68.9 \%$

$81.7 \%$

Asian

$76.7 \%$

$94.1 \%$

Age

$<26$

$70.3 \%$

$85.6 \%$

$26-64$

$77.4 \%$

$88.5 \%$

$65+$

$96.7 \%$

$99.0 \%$

Notes. The data for the U.S. population is from 2020 Current Population Survey tabulations, available at: https://www.census.gov/content/dam/Census/library/publications/2021/demo/p60274.pdf. 
Table 8. Retirement Savings of Respondents and U.S. Adults

401(k)

Company pension

IRA

Other

No retirement savings account
Uber

$36.0 \%$

U.S.

$54.4 \%$

$10.6 \%$

$21.3 \%$

$14.8 \%$

$32.8 \%$

$3.5 \%$

$53.3 \%$

Notes. The U.S. data comes from the Survey of Household Economics and Decisionmaking (2020), available at: https://www.federalreserve.gov/consumerscommunities/shed data.htm. The U.S. respondents are adults who do not consider themselves retired.

Table 9. Available Savings Reported by Respondents and U.S. Adults

Uber

U.S.

Percent of respondents who can cover $\$ 400$ emergency expense

Notes. The U.S. data comes from the Survey of Household Economics and Decisionmaking (2020), available at: https://www.federalreserve.gov/consumerscommunities/shed data.htm. 
Table 10. Interest in Participating in an Automatic Savings Program

\author{
Percent who \\ would \\ participate
}

Saving into a flexible benefits account

Saving into a retirement savings account

\author{
Avg. weekly \\ target amount
}

$\underline{\text { Scenario } 1}$

$58.4 \%$

$\$ 601$

2.13

Avg. ratio of

target amount

to weekly

earnings

\section{$\underline{\text { Scenario } 2}$}

$\$ 774$

2.64

\section{If not interested in Scenario 1 or 2}
Saving with matching contributions
$44.1 \%$
$\$ 550$
1.80

Notes. The respondents were asked if they would be willing to participate in a program that helps them save more. They would choose a weekly target for earnings from rideshare and delivery work, and if they exceed this target, any additional earnings would be automatically transferred to a special account. Fifty percent of the people were asked about a flexible benefits account and fifty percent - about a retirement savings account. If a respondent answered "No", they were asked if they would be willing to participate in a program where their contributions to the account were matched. The distribution of reported target amounts is trimmed to exclude 1 percent of extreme values. Average ratio of target amount is calculated only for the respondents who earned all rideshare/delivery income using one app. Weekly earnings are from Uber administrative data and are calculated as average weekly earnings over the last 12 months. 